BNL 50563

$\frac{2}{4}$

A. 893

\title{
OPTIMIZATION OF WATER CONVEYANCE SYSTEMS FOR NUCLEAR ENERGY CENTERS
}

\author{
Peter M. Meier
}

\section{September 1976}

\section{POLICY ANALYSIS DIVISION}

NATIONAL CENTER FOR ANALYSIS OF ENERGY SYSTEMS BROOKHAVEN NATIONAL LABORATORY

UPTON, NEW YORK II973 


\section{DISCLAIMER}

This report was prepared as an account of work sponsored by an agency of the United States Government. Neither the United States Government nor any agency Thereof, nor any of their employees, makes any warranty, express or implied, or assumes any legal liability or responsibility for the accuracy, completeness, or usefulness of any information, apparatus, product, or process disclosed, or represents that its use would not infringe privately owned rights. Reference herein to any specific commercial product, process, or service by trade name, trademark, manufacturer, or otherwise does not necessarily constitute or imply its endorsement, recommendation, or favoring by the United States Government or any agency thereof. The views and opinions of authors expressed herein do not necessarily state or reflect those of the United States Government or any agency thereof. 


\section{DISCLAIMER}

Portions of this document may be illegible in electronic image products. Images are produced from the best available original document. 
BNL 50563

(Environmental Control Technology

and Earth Sciences - TID-4500)

\title{
OPTIMIZATION OF WATER CONVEYANCE SYSTEMS FOR NUCLEAR ENERGY CENTERS
}

Peter M. Meier

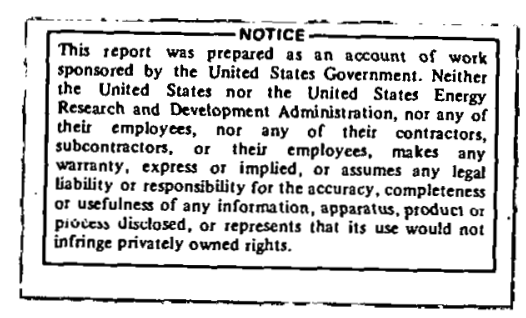

September 1976

\author{
POLICY ANALYSIS DIVISION \\ NATIONAL, CENTER FOR ANALYSIS OF ENERGY SYSTEMS \\ BROOKHAVEN NATIONAL LABORATORY \\ ASSOCIATED UNIVERSITIES, INC. \\ UPTON, NEW YORK 11973
}

Prepared for the

DIVISION OF BIOMEDICAL AND ENVIRONMENTAL RESEARCH

UNITED STATES ENERGY RESEARCH AND DEVELOPMENT ADMINISTRATION

UNDER CONTRACT NO. EY-76-C-02-0016 


\section{N O T I C E}

This report was prepared as an account of work oponoored by the Unitcd States Government. Neither the United States nor the United States Energy Research and Development Administratiogn. nor any of their employees. nor any of their rinntrasitnrs. subcontractors, or their employees, makes any warranty, express or implied, or assumes any legal liability or responsibility for the accuracy, completeness or usefulness of any information, apparatus, product or process disclosed, or represents that its usc would not infringe privately owned rights.

Printed in the United States of America Available from

National Technical Information Service U.S. Department of Commerce

5285 Port Royal Road

Springfield, VA 22161

Price: Printed Copy $\$ 5.00$; Microfiche $\$ 3.00$

January 1977

455 copies 
This study is one of a continuing series of reports on Energy Center Siting sponsored by the U.S. Nuclear Regulatory Commission and the Division of Biomedical and Environmental research of the U.S. Energy Research and Development Administration, prepared by the Brookhaven National Laboratory Energy Policy Analysis Division.

To date, the Brookhaven National Laboratory energy center research effort has focused on an evaluation of a hypothetical Nuclear Energy Center in New Jersey and the development and application of specific analytical tools necessary for policy assessments. It is to the latter area that this report is addressed.

Other reports in this series include:

Energy Policy Analysis Group, et al. "A Preliminary Assessment of a Hypothetical Nuclear Energy Center in New Jersey", BNL-50465, Nov. 19.75.

P.M. Meier and D. Morell "Issues in Clustered Nuclear Siting: A Comparison of a Hypothetical Nuclear Energy Center in New Jersey with Dispersed Nuclear Siting", BNL-50561.

Regional Science Department, University of Pennsylvania, "Regional Economic Impacts of Nuclear Power Plants", BNL-50562.

F. Moore and J. Zakaria, "Noise from Cooling Towers of Power Parks," BNL-50564.

S. Linke and D. Chu, "Transmission Studies of Dispersed vs. Clustered Generating Facilities," BNL-50565. 


\section{ACKNOWLEDGEMENT}

The writer is indebted to Dr. D. McCreath, of Acres American, Inc., Buffalo, New York, for his assistance in matters of soft ground tunneling technology, and to Dr. J.E. Edinger, of J.E. Edinger Associates, Wayne, Pennsylvania, for his advice and guidance in the analysis of water resource problems of Nuclear Energy Centers. The assistance of Bob Stern in preparing the graphics, and of Adele Hough in typing, is also gratefully acknowledged. The rcaponsibility for the accuracy and opinivis expressed lin this report, however, remains entirely with tlit wi ilès. 
TABLE OF CONTENTS

Chapter

$\underline{\text { Page }}$

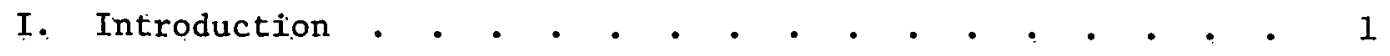

II. Cost Function Derivation . . . . . . . . . . . 7

III. The Single Time Period Model . . . . . . . . . . 25

IV. Electrical System Reliability and Water Conveyance Cost . . 41

V. The Multi-Time Period Model . . . . . . . . . . . 53

VI. Relationship to Cooling System Configuration . . . • . 65

VII. Comparison with the Dispersed Case . . . . . . . . . 73

VIII. Siting Trade-offs • • • • • • • • • • • • • • • 79 


\begin{abstract}
This report develops a mathematical model for the conceptual design of water supply systems for nuclear energy centers based on a classical optimization analysis under inequality constraints and an embedded enumeration scheme. A hypothetical nuclear energy center in New Jersey is used for illustrative computations and sensitivity analysis to major design variables. The optimization criterion is the minimization of present worth over the lifespan of the center, and encompasses all major components of the cooling, water conveyance and heat dissipation systems. Analysis of the trade-off between electric transmission and water conveyance, and comparicons of cooling system modes are alsu included.
\end{abstract}




\subsection{Background}

This report is one of several technical studies conducted by the BNL Regional Studies Program in connection with an evaluation of a hypothetical nulcear energy center (NEC) in Ocean County, New Jersey. As such, it addresses only the rather narrow technical area of water conveyance and cooling systems; the comprehensive evaluation of all facets of the NEC is reported in a separate study, to which the reader is referred for further background. 1

A number of reasons justified the detailed effort in the analysis of water conveyance systems. First, Ocean County was initially selected for study by the U.S. Regulatory Commission in order to illustrate NEC siting problems in an area close to major metropolitan areas, and to illustrate once through cooling. But our preliminary assessment, based admittedly on rather approximate computations, indicated that despite the proximity of the NEC to the coast, once-through cooling proved to be more expensive than evaporatively cooled alternatives. ${ }^{2}$ Verification of this preliminary finding demanded more detailed analysis.

A second reason for more detailed study was the fact that the analysis of water conveyance systems conducted by the NRC for its generic evaluation of NEC' $s^{3}$ did not address a number of features encountered in the Ocean County case. The most important difference was the fact that for reasons of environmental impact and land use, bored tunnels rather than conventional cut-and-fill pipelines were found to be necessary. Water conveyance system costs would thus likely be a much more important component of total system cost than in the other surrogate case studies examined; and, as such, warranted a much closer scrutiny than elsewhere necessary.

It should be pointed out that the intent of our New Jersey NEC analyses, which were conducted in support of the U.S. Nuclear Regulatory Commission Nuclear Energy Center Site Survey (NECSS), was to inject a local and regional perspective into the broad national assessment of energy centers; 
since only by reference to specific sites could many of the technical, environmental, institutional and socioeconomic issues be adequately addressed. Indeed, in addition to the New Jersey study area a number of other potential areas were selected throughout the. U.S. for more specific analysis, each typical of a representative set of siting attributes. ${ }^{4}$ Thus neither Ocean County, nor any of the other surrogate sites, is recommended for consideration for actual construction. of an NEC; nor does the selection of study areas imply any judgement of desirability. Similarly the three "sites" mentioned in this report were selected merely for the purpose of conducting engineering computations, and were not selected on grounds of a detailed site screening or even an environmental impact study. The objective in selecting surrogate sites, then, was not to find the best locations, but to select sites that would illustrate the broadest range of potential issues. And in the narrow context of this report, the three study sites serve merely to illustrate application of the analytical models.

Finally one might note that although the analytical approach was designed to address the complexities of a dynamic planning problem, spanning, in the case selected for case study, a period of some 27 years over which period some twenty 1200Mw reactors and their associated water conveyance systems would be built, the methodology can readily by used for smaller agglomerations of reactors, and is even suitable for the single unit nuclear station. Moreover, none of the model's features are specific to nuclear reactors, and could thus equally be used for analysis of cooling alternatives for fossil power plants. The computer program that performs the computations derived in this report is documented in a separate report. ${ }^{5}$

\subsection{The Reference Sites}

As noted above, three reference sites were chosen within Ocean County for purposes of more detailed analysis (Figure 1). ${ }^{6}$ For purposes of the comprehensive assessment reported elsewhere, ${ }^{7}$ each site was assumed to have a different cooling configuration; the Bay Site was to be once-through cooled, the Inland Site was to be cooled by mechanical draft, hybrid wet/dry towers, and the Fort Dix site by natural draft evaporative towers. The corresponding water use assumptions are shown on Table 1 . However, even though all of the base case computations are for this specification of alternatives, in Chapters VI and VIII of this report we examine the effect of allowing 


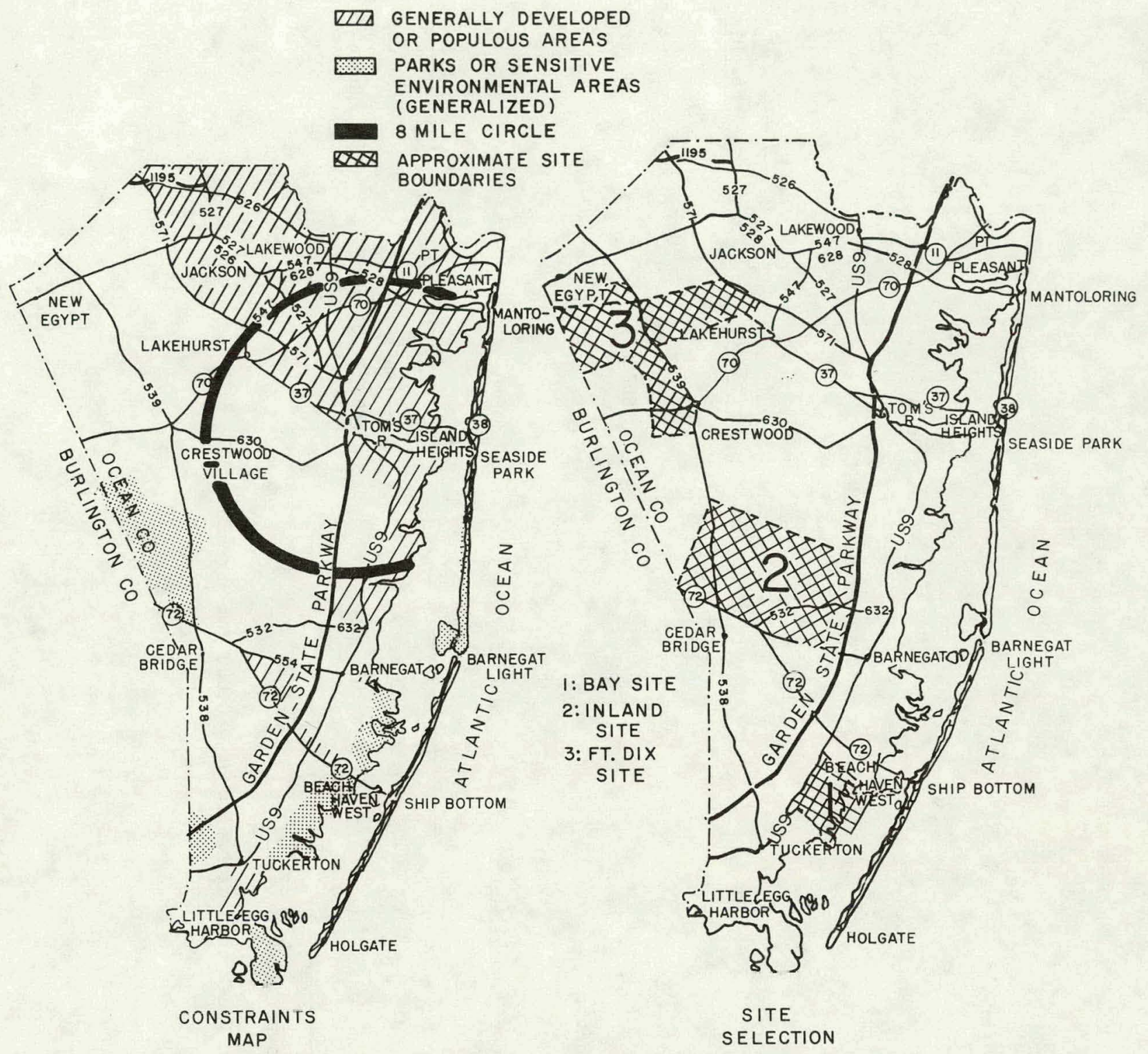

Figure 1. Constraints map and site selection. Source: Mcier \& Morell, Note 1 . 
Table 1

WATER REQUIREMENTS

Bay

(E)

Concentration Factor

(N)

Once-through Water Requirement ${ }^{3}$

$$
\begin{gathered}
\left(=17.42 \times 10^{6} \mathrm{gpm}\right) \\
\frac{38,900 \mathrm{cfs}}{\left.i=17.42 \times 10^{6} \mathrm{gpm}\right)}
\end{gathered}
$$

Total Water Use (Q)
Inland

600 efs

1.45

0

$1933 \mathrm{c}=\mathrm{s}$

$\left(=.868 \times 10^{6} \mathrm{gpm}\right)$
Ft. Dix

$600 \mathrm{cfs}$

1.45

0

1933 cfs

$\left(=.868 \times 10^{6} \mathrm{gpm}\right)$

$a_{b a s e d}$ on $30 \mathrm{c}$ Es per $1200 \mathrm{Mw}(\mathrm{e})$

${ }^{b}$ based on Oystar Creek condensor $=1$ ow of 450,000 gpm per 520 Yiw (e) 
different cooling modes at each of these sites.

\subsection{Scope of this Report}

We turn first, In Chapter IT, to a derivation of the cost functions to be used in subsequent model building. Such functions are derived for all of the major components of a water supply and conveyance system, as well as for cooling towers and diffuser systems. In order to facilitate the understanding and development of the optimization model, we then turn, in Chapter III, to a single-time period formulation of the conveyance system optimization problem. The approach is based on a classical optimization analysis under inequality constraints for pipe diameter determination, coupled with a complete enumeration scheme for system configuration.

Chapter IV examines the relationship between the reliability of the reactor-generating systems and water conveyance system design; it can be shown that proper consideration of scheduled maintenance and forced outages allows considerable savings in the water conveyance and cooling system cost for a large NEC.

A dynamic, multi-period model is then developed in Chapter V. In contrast to the single time-period model that used minimization of the (constant) annual cost as an optimfzation criterion, the proper measure in the dynamic case is the minimization of present worth. The results yielded by this formulation are then subjected to a sensitivity analysis in Chapter VI, in which we examine the impact of a number of important design variables on optimum system configuration.

Chapter VII presents a comparison of the New Jersey NEC water conveyance system costs with that of an equivalent number of dispersed nuclear plants. Chaper VIII examines twn important trade-offs; between water transmission and electrical transmission, of some importance to the siting decision-- and between surface cut-and-fill pipeline conduits and bored tunnels, of importance to locations similar to Ocean County where land use and environmental considerations preclude conventional surface conduits. 
1. P. Meier and D. More11, "Issues in Clustered Nuclear Siting: A Comparison of a Hypothetical Nuclear Energy Center in New Jersey With Dispersed Siting," BNL 50561 (June 1976), Brookhaven National Laboratory.

2. Energy Policy Analysis Group," Preliminary Assessment of a Hypothetica1 Nuclear Energy Center in New Jersey," BNL 50465 (Nov. 1975), Brookhaven National Laboratory.

3. U.S. Nuclear Regulatory Commission, "Nuclear Energy Center Site Survey 1975," NUREG-0001 (Jan. 1976), 5 Volumes. (Hereinafter cited as NRC-NECSS.)

4. The Kentucky Lake site was chosen on the basis of being representative of an inland river site, cooled by evaporative towers, with power transmitted in all direcllons from the Cencer. The New York site was representative of a remote site; with power transmitted over rplatively lomg distancos to one or lwu majul Iuad enllers. The Eastern Nevada site was representative of a very remote site cooled principally by dry towers. (See NRCNECSS, Note 3, supra, Executive Summary, p.10.)

5. P. Meier, "NECWSO - A Computer Code for Water Conveyance System Optimization: User Manual and Documentation," BNL Regional Energy Studies Program, forthcoming report.

6. For a discussion of the site selection process within Ocean County, see Meier and More11, Note 1, supra, Chapter V.

7. Meier and More11, Note 1, supra; especially Chapters VIII through XII. 


\section{COST FUNCTION DERIVATION}

\subsection{Introduction}

The objective of this Chapter is to establish cost functions for each of the major subsystems. These functions are all expressed in terms of the Engineering News Record Index ("ENR-Index") of construction costs, thus allowing subsequent computations to reference any given timepoint by a simple indexing procedure. The annual average values of this construction cost index over the past few years are as follows:

$\begin{array}{ccc}\text { Year } & & \text { ENR-Index } \\ 1968 & 11.54 \\ 1969 & 1270 \\ 1970 & 1379 \\ 1971 & 1570 \\ 1972 & 1725 \\ 1973 & 1896 \\ 1974 & 2019 \\ \text { Mid 75 } & 2205\end{array}$

The only operating cost explicitly considered in our analysis is the energy cost for pumping, which can be adjusted to any given price level by choice of the appropriate cost per kwh. No demand charges are included in the analysis. $\underline{2.2}$ Soft-Ground Tunne1s ${ }^{1}$

Because of the significant variation in tunneling costs through the type of unconsolidated coastal sediments that would be encountered on the New Jersey Atlantic Coast, there is some difficulty in establishing a well defined cost function. There do exist some rather sophisticated computer programs for preliminary engineering cost estimates, but the amount of geological and design information required goes beyond the resources of an initial feasibility study. ${ }^{2}$ We resorted, therefore, to the simple expedient of a statistical analysis of data contained in a published survey of soft ground tunnels. ${ }^{3}$ 
A multiple regression of construction cost in \$ per ft. of length, y, on tunnel diameter in $\mathrm{ft} ., \phi$, resulted in the equatton ${ }^{4}$

$$
y=4.0195 \phi^{2.15}
$$

with correlation coefficient .74 , and 55 percent of the variation in unit cost explained by variation of tunnel diameter. ${ }^{5}$ The numerical value of the exponent is rather interesting; if tunnel costs were an exact function of the excavation volume, the exponent would be exactly 2 .

A number of further adjustments are necessary. First, because a soft ground tunnel will be lined, the diameter of the lined tunnel, $\phi$, used in subsequent hydraulic computations, is not equal to the outside diameter that determines cost. ${ }^{6}$ Thus, if the lining thickness is some fraction of radius, say $\tau$,

$$
\begin{aligned}
\phi_{0} & =\phi+\tau \phi \\
& =\phi(1+\tau)
\end{aligned}
$$

hence the adjusted cost function in terms of $\phi$ is

$$
y=4.019(1+\tau)^{2.15} \phi^{2.15}
$$

Second, since this function is in 1973 dollars, we make the previously discussed adjustment for ENR-Index. Thus

$$
y=\frac{4.019}{1896} \operatorname{ENK}(1+\tau)^{2.15} \phi^{2.15}
$$

For a typical value of $\tau=0.05,{ }^{7}$ we thus have a unit cost of tunneling, in $\$ / f t$ of length, of

$$
\mathrm{y}=\mathrm{k}_{1} \text { ENR } \phi^{2.15}
$$

where $k_{1}=.00235$

The amortizel annual cost'for a tunnel of length $\ell$ is therefore given by

$$
\ell \operatorname{ENR~} k_{1} \operatorname{CRF}(i, n) \phi^{2.15}
$$

where CRF $(i, n)$ is the capital recovery factor for interest rate $i$ over $n$ ycars. 


\section{$\underline{2.3 \quad \text { Pumping Energy Costs }}$}

Pumping energy costs are a function of the static head (i.e., the difference in elevation between the NEC and mean sea level) and the dynamic head (due to friction losses) which is a function of pipe and flow characteristics.

The horsepower needed to overcome static head is given by the we11 known equation

$$
P_{s}=\frac{Q \gamma h_{s}}{550 \eta}
$$

where $h_{s}$ is the static head in $f t$.

$\gamma$ is the density of water, in $1 b / c u$. $f t$.

$\eta$ is the pump efficiency, say .85

Hence the pumping costs per year are given by

$$
\begin{aligned}
C_{p s} & =0.746\left[\frac{\mathrm{kw}}{\mathrm{HP}}\right] 365.24\left[\frac{\mathrm{hrs}}{\mathrm{yr}}\right] \propto\left[\frac{\mathrm{S}}{\mathrm{kwh}}\right] \mathrm{P}_{\mathrm{S}}[\mathrm{HP}] \\
& =\frac{11.881 \alpha Q \gamma \mathrm{h}_{\mathrm{s}}}{\eta}
\end{aligned}
$$

The friction losses may be computed by the Manning equation, namely ${ }^{8}$

$$
h_{f}=\frac{2.87 n^{2} \ell v^{2}}{\phi 1.333}
$$

where $h_{f}=$ friction head, ft.

$\ell=$ length of conduit, ft.

$\mathrm{n}=$ Manning coefficient

$\mathrm{V}=$ flow velocity, in $\mathrm{ft} / \mathrm{sec}$

hence the horsepower needed to overcome friction losses is

$$
\mathrm{HP}_{\mathrm{f}}=\frac{Q \Upsilon 2.87 \mathrm{n}^{2} \cdot \ell \mathrm{V}^{2}}{550 n \phi^{1.333}}
$$

and the cost is

$$
C_{f}=\frac{11.88 \alpha Q \gamma 2.87 \mathrm{n}^{2} \ell \mathrm{v}^{2}}{n \phi^{1.333}}
$$


But for a given flow $Q$, and pipe diameter $\phi$, the velocity is given by

$$
V=\frac{Q}{A}=\frac{4 Q}{\pi \phi^{2}}
$$

hence, substituting into (5), we obtain

$$
c_{\mathrm{pf}}=\frac{55.23 \alpha Q^{3} \gamma \mathrm{n}^{2} \ell}{n \phi^{5.333}}
$$

The total pumping energy cost is thus the sum of (3) and (6), i.e.,

$$
C_{p}=\frac{11.881 \alpha Q \gamma h_{s}}{n}+\frac{55.23 \alpha Q^{3} \gamma n^{2} \ell}{n \phi 533}
$$

\subsection{Pumping Stations}

The capltal cost of pumps are best expressed in terms of installed horsepower, for which the Corps of Engineers has developed the relationship as shown In Figure 2. For the horsepower range of interest, we assume that the curve can be approximated by the exponential function

$$
\frac{\mathrm{C}\left(\mathrm{HP}_{1}\right)}{\mathrm{C}\left(\mathrm{HP}_{2}\right)}=\left(\frac{\mathrm{HP}_{1}}{\mathrm{HP}_{2}}\right)^{\mathrm{b}}
$$

where $\mathrm{C}(\mathrm{HP})$ is the total cost for a pumping station of horsepower $\mathrm{HP}_{1}$. Hence if $\mathrm{C}^{\prime}(\mathrm{hp})$ is the cost per horsepower,

$$
\frac{\mathrm{C}^{\prime}\left(\mathrm{hp}_{1}\right) \mathrm{HP}_{1}}{\mathrm{C}^{\prime}\left(\mathrm{hp}_{2}\right) \mathrm{HP}_{2}}=\left(\frac{\mathrm{HP}_{1}}{\mathrm{HP}_{2}}\right)^{\mathrm{b}}
$$

or

$$
\frac{\mathrm{C}^{\prime}\left(\mathrm{hp}_{1}\right)}{\mathrm{C}^{\prime}\left(\mathrm{hp}_{2}\right)}=\frac{\mathrm{HP}_{2}}{\mathrm{HP}_{1}}\left(\frac{\mathrm{HP}_{1}}{\mathrm{HP}_{2}}\right)^{\mathrm{b}}
$$

But from F1gure 2, we note that for $\mathrm{HP}_{1}=3200, \mathrm{HP}_{2}=200$; thus, insertion of these values yielde

$$
\frac{400}{800}=\frac{200}{3200}\left(\frac{3200}{200}\right)^{h}
$$

from which b solves to 


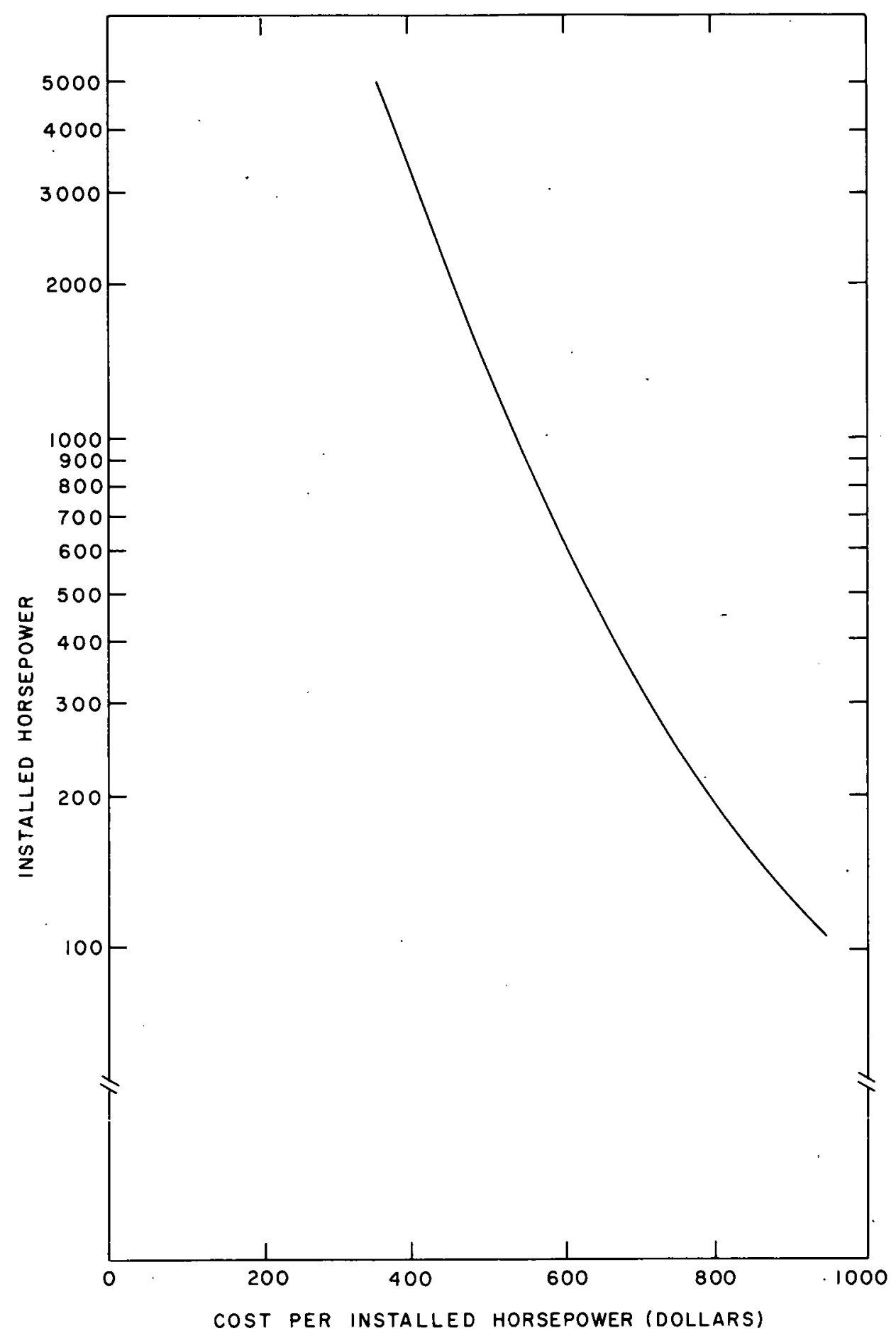

Figure 2. Cost of pumping stations.

Source: North Atlantic Regional Water

Reoourceo Study, Notc 9. 


$$
b=\frac{\log _{e} 8}{\log _{e} I 6}=0.75
$$

The cost function, in 1970 construction dollars as a function of installed horsepower, is thus given by

$$
\mathrm{C}(\mathrm{HP})=3008 \mathrm{HP}^{0.75}
$$

but since the horsepower required are given by the expression

$$
H P=\frac{Q \gamma\left(h_{f}+h_{s}\right)}{\eta 550}
$$

we obtain for the construction cost the equation

$$
C(H P)=3008\left(\frac{Q \gamma h_{s}}{n 550}\right)^{0.75}+3008\left(\frac{Q \gamma 2.87 n^{2} \ell 16 Q^{2}}{\eta 550 \pi^{2} \phi^{5.333}}\right)^{0.75}
$$

These costs are for 1970, and thus the indexing procedure yields the general cost function

$$
\mathrm{C}(\mathrm{HP})=k_{3} \operatorname{ENR}\left(\frac{\mathrm{Q} \mathrm{h}_{\mathrm{s}}}{n}\right)^{0.75}+k_{4} \operatorname{ENR}\left(\frac{\gamma^{2} \ell Q^{3}}{n \phi^{5.333}}\right)^{0.75}
$$

where $k_{3}=0.0192$ and $k_{4}=0.06082$.

\subsection{Storage Reservoius}

A good source for reservoir construction cost data in the study area is again the NAR report, 10 as shown in Figure 3. Subregion "D" of that report corresponds to the Delaware Basin and Subregion "E" to the Susquehanna.

Again we assume an exponential cost function of the form

$$
\frac{C\left(\mathrm{AF}_{1}^{\prime}\right)}{\mathrm{C}\left(\mathrm{AF}_{2}\right)}=\left(\frac{\mathrm{AF}_{1}}{\mathrm{AF}_{2}}\right)^{\boldsymbol{\alpha}}
$$

where AF denotes the storage volume of the reservoir in acre-ft. 


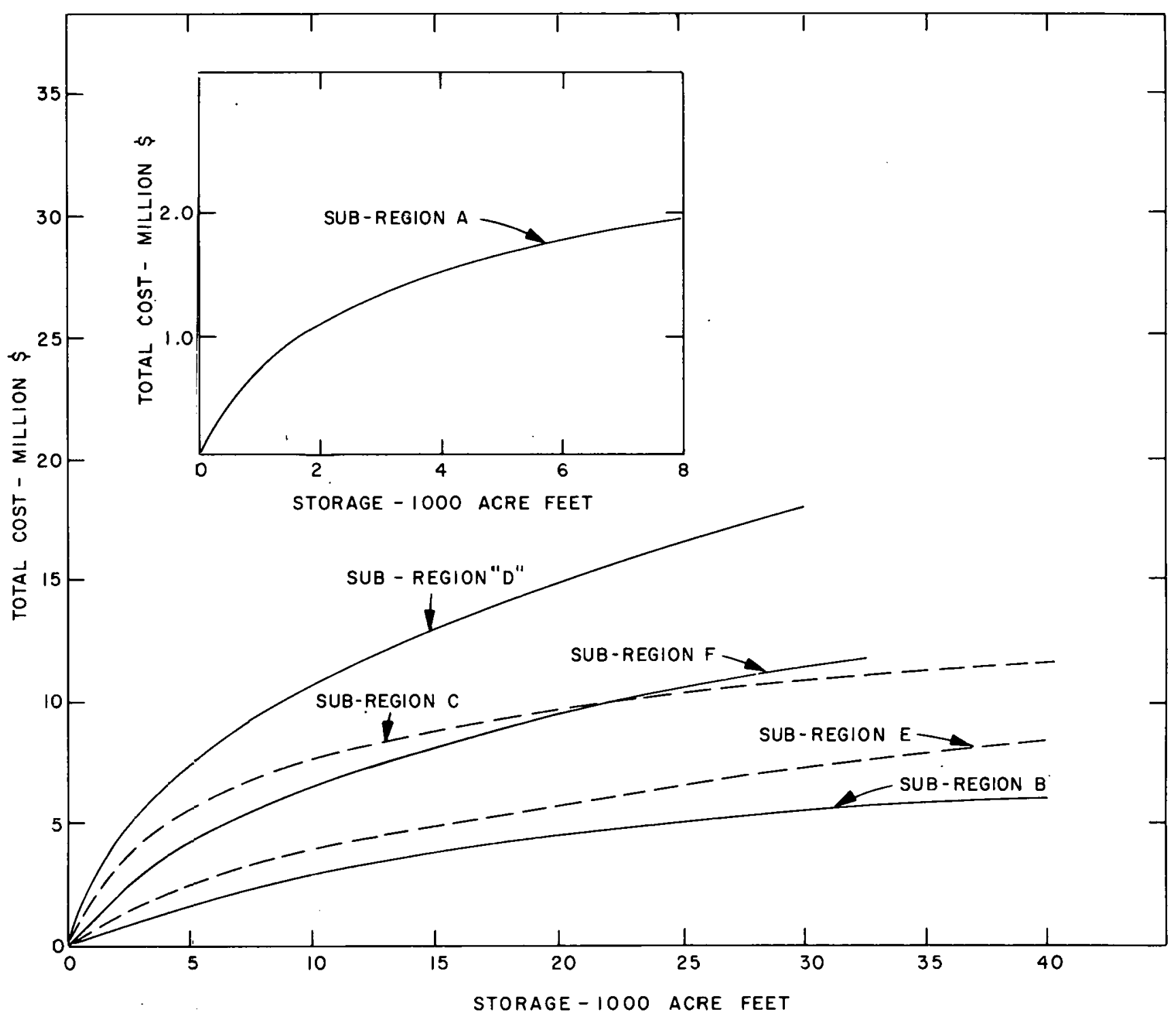

Figure 3. Cost functions for reservoir construction. Source: North Atlantic Regional Water Resources Study, Note 9. 
Using the same procedure as used in Section 2.4 for pumping station costs, we derive two storage reservoir cost functions as

$$
\begin{aligned}
& C_{1}(A F)=137206 A^{.4725} \quad \text { (Delaware) } \\
& C_{2}(A F)=23908 \cdot A F^{.5506} \quad \text { (Susquehanna) }
\end{aligned}
$$

These costs, however, represent average 1970 cost levels; to bring them to the ENR index-1inked cost, we make the usual adjustment to yield

$$
\begin{aligned}
C_{1}(\mathrm{AF}) & =\operatorname{ENR} \frac{137207}{1379} \mathrm{AF} \cdot 4725 \\
& =\operatorname{ENR} 99.16 \mathrm{AF} \cdot 4725 \\
C_{2}(\mathrm{AF}) & =\operatorname{ENR} \frac{23908}{1379} \mathrm{AF} \cdot .4275 \\
& =\operatorname{ENR} 17.33 \mathrm{AF} \cdot 5506
\end{aligned}
$$

One should note that the storage requirement is a function of the incremental safe yield required; for the Delaware River Basin every cfs of additional flow requires some 420 acre-ft. of reservoir storage. ${ }^{11}$ A similar value is assumed for the Susquehanna Basin.

\subsection{Surface Conduits}

In the case of a buried, near-surface conduit, the following costs must be considered in place of the tunnel costs of Section 2.2 and 2.3;

1. Excavation and backfill costs (which are some function of the volume of earth excavated).

2. The pipe cost (some function of pipe diameter).

3. Right-of-way costs (some function of pipe and excavation width).

The excavation volume is given by the product of trench depth $d$, trench width $w$, and trench length $\ell$. Using the relationships of the NRC Generic assessment, ${ }^{12}$

$$
\begin{aligned}
& a=\phi+.5 \\
& w=\left(0.5+3 n^{*}\right) \phi
\end{aligned}
$$


where $n *$ is the number of pipes in the trench, and $d, w$, and $\phi$ are in $f t$. Hence excavation costs for a trench of length $l$, containing $n^{*}$ pipes, is

$$
\frac{\Omega_{1}}{27}(\phi+5)(0.5+3 n *) \phi \ell
$$

where $\Omega_{1}$ is the cost per cubic yard of volume. Now in practice, each trench would contain one intake pipe and one discharge pipe," which, as we shall note later on, may be of different diameters. Because of the scale economies in trench digging, one would certainly avoid digging two separate trenches for intake and discharge if both are built at the same time. Moreover, scale economies in the pipe costs and friction losses would always mandate a single pipe for discharge and a single pipe for the intake, rather than several smaller diameter pipes. Consequently, the excavation cost per conduit (remembering that we define a conduit as one intake and one discharge pipe) is

$$
\begin{aligned}
y_{e} & =\frac{\Omega_{1}}{27}\left(\phi_{I}+5\right)(0.5+3 \times 2)\left(\frac{\phi_{I}+\phi_{D}}{2}\right) \ell \\
& =0.12 \Omega_{I}\left(\phi_{I}+5\right)\left(\phi_{I}+\phi_{D}\right) l
\end{aligned}
$$

If $\Omega_{2}$ is the right-of-way cost in $\$$ per acre, then the total right-of-way cost, $y_{w}$, can be expressed as

$$
\begin{aligned}
\mathrm{y}_{\mathrm{w}} & =\frac{\Omega_{2}}{43560} \ell(\mathrm{w}+80) \\
& =\frac{\Omega_{2}}{43560} \ell 6.5\left(\frac{\phi_{I}+\phi_{D}}{2}\right)+80 \\
& =0.00183 \Omega_{2} \ell+0.0000746 \Omega_{2} \ell\left(\phi_{I}+\phi_{D}\right)
\end{aligned}
$$

Finally, the pipe costs $y_{p}$ are given by

$$
\mathrm{y}_{\mathrm{p}}=\Omega_{3} \ell\left(\phi_{\mathrm{I}}+\phi_{\mathrm{D}}\right)
$$

where $\Omega_{3}$ is the unit cost of pipe.

Collecting terms, the total conduit cost $y_{c}$, is 


$$
\begin{aligned}
y_{C}= & 0.12 \Omega_{I}\left(\phi_{I}+5\right)\left(\phi_{I}+\phi_{D}\right) \ell+0.00183 \Omega_{2} \ell \\
& +0.0000746 \Omega_{2} \ell\left(\phi_{I}+\phi_{D}\right)+\Omega_{3} \ell\left(\phi_{I}+\phi_{D}\right)
\end{aligned}
$$

hence,

$$
\begin{aligned}
y_{C}= & \ell\left(\phi_{I}+\phi_{D}\right)\left\{\Omega_{3}+0.12 \Omega_{1}\left(\phi_{I}+5\right)+0.0000746 \Omega_{2}\right\} \\
& +\ell \Omega_{2} 0.00183
\end{aligned}
$$

In the case of a once-through cooled plant, $\phi_{I}=\phi_{D}$, say, $\phi$, and thus Eq. (15) becomes

$$
\begin{aligned}
\mathrm{C}_{\mathrm{OT}} & =2 \ell^{\prime} \phi\left\{\Omega_{3}+0.12 \Omega_{1}(\phi+5)+0.0000746 \Omega_{2}\right\} \\
& +0.00183 \Omega_{2} \ell^{\prime}
\end{aligned}
$$

In the evaporatively cooled case, for which intake diameter is greater than discharge diameter, matters are more complex because each conduit must be optimized separately. (See below, Section 3.3) While this may cause few problems in the tunnel case, since separate tunnels are needed for intake and discharge, in the buried pipe case, the presence of a shared trench poses some difficulty.

Some approximations, however, appear to be adequate. In the dotormination of optimal diameter, we can simply assulie that as fas as the pipe trench term is concerned, intake and discharge are in fact of equal diameter. We can also, arbitrarily, assign the right-of-way and excavation cost to the discharge, and only assign actual pipe costs to the intake. This is quite allowable provided the intake and discharge are, in fact, put into the same trench, and the above assignment is merely a matter of accounting. Thus the intake cost would be given by

$$
\mathrm{y}_{I} \doteq \ell^{\prime} \Omega_{3} \phi_{I}
$$

and the discharge cost by

$$
y_{D}=\rho^{\prime} k \phi_{D} 2.15
$$


The NRC NECSS uses the following numerical values: ${ }^{13}$

$\Omega_{1}=\$ 3.75$ per cu. yd.

$\Omega_{2}=\$ 500$ per acre

$\Omega_{3}=\$ 20$ per $\mathrm{ft}$ of diameter

Since these are in 1973 costs, we apply the usual indexing procedure to the cost functions derived in this section to allow easy updating of the model.

\subsection{Intake-discharge structure}

The intake-discharge structure costs have been stated as

$$
C_{i d}=4.5 q^{\prime}\left(\frac{10^{6}}{q^{1}}\right)^{0.7}
$$

where $\mathrm{q}^{\prime}$ is in gallons per minute. This may be rewritten in terms of cubic $f t$. per second (cfs) as

$$
\begin{aligned}
C_{\text {id }} & =4.5448 .8 Q\left(\frac{10^{6}}{448.8 Q}\right)^{0.7} \\
& =4.454 \times 10^{5} Q^{0.3} \\
& =234.91 \mathrm{ENR} Q^{0.3} \\
& =k_{2} \text { ENR } Q^{0.3}
\end{aligned}
$$

\subsection{Diffuser System}

The design of an off-shore diffuser system is a problem of some complexity, involving difficult analysis of coastal hydrodynamics and manifold hydraulics. ${ }^{15}$ In the type of conceptual analysis undertaken in this report we can therefore capture only the most important tradeoffs, with the result that only gross feasibility and order of magnitude costs can be established. For purposes of this analysis we shall assume 
that the diffuser system is of the multi-port, submerged type, resting on the ocean bed parallel to the coastline. The major questions of interest concern the length of the diffuser system, and its distance off-shore, since these two variables are the major influences on system cost. We sha1l also assume that a preliminary analysis of thermal and hydrodynamic conditions is available, resulting in the type of curve shown on Figure 4 that describes the requisite length of diffuser necessary for given excess surface temperature and given water depth. This relationship also describes the most important trade-off to be considered: the deeper the water depth, the shorter the length of diffuser necessary to meet prescribed thermal limits at the surface. But the greater the water depth, the greater the distance from the shoreline, and thus the greater the length, and cost, of the discharge conduit.

Suppose that for given surface temperature excess $\Delta \mathrm{T}_{\mathrm{S}}$ the relationship between nozzle submergence depth $\delta_{d}$ and diffuser length per $1000 \mathrm{MW}(\mathrm{e}), \Delta_{\rho}$, is described by the equation

$$
\Delta_{\rho}=a_{1} e^{-b_{1} \delta} d
$$

Then the relationship between water depth $\delta_{d}$, the distance offshore, $\ell_{D}$, and the average slope of the ocean floor, $\rho$, is as shown on Figure 5.

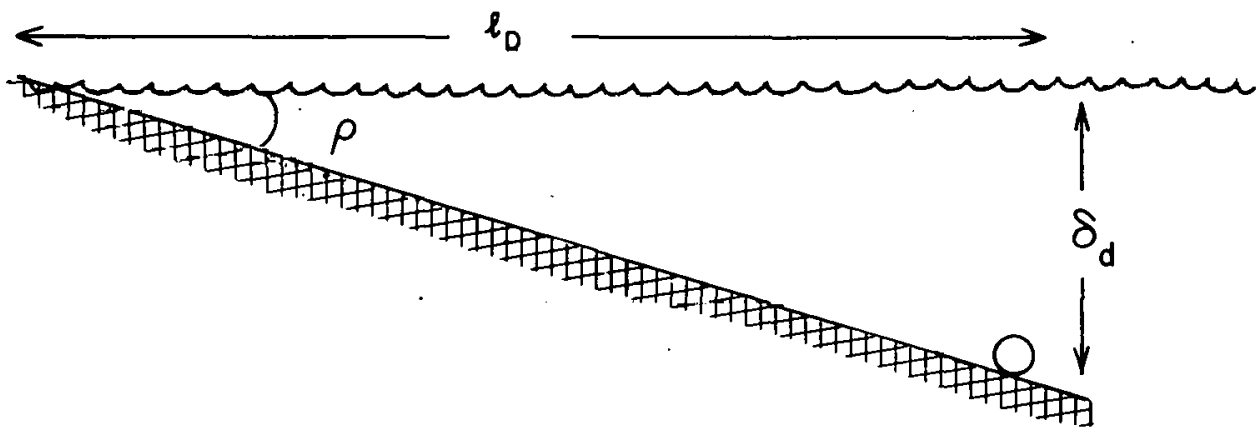

Figure 4. Definition of $\delta_{d}$. 


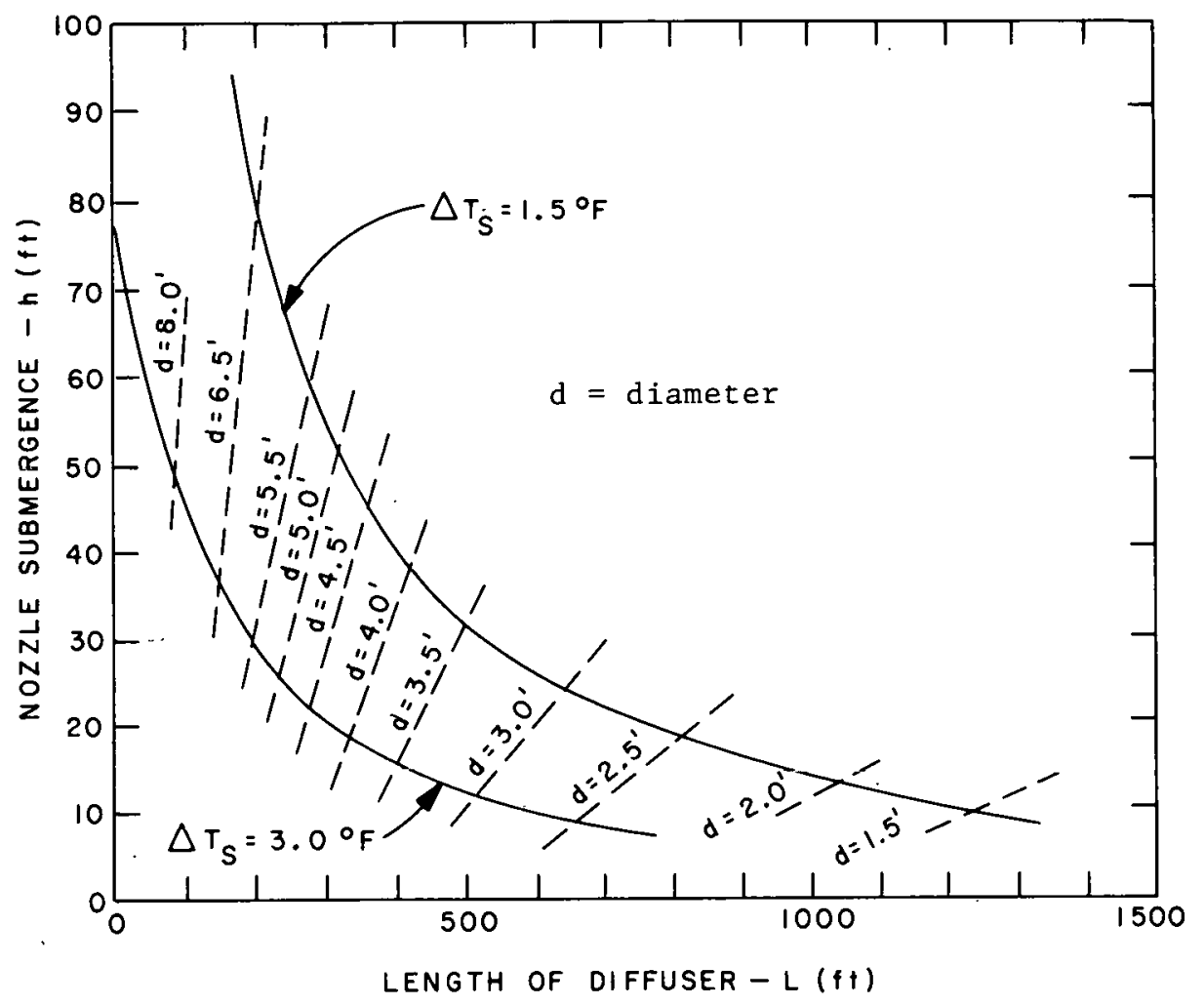

Figure 5. Relationship of diffuser length to nozzle submergence. Source:

Brodfeld, Note 16 . 
And from this it is clear that

$$
\delta_{d}=\ell_{D} \tan \rho
$$

consequently the total diffuser length $\Delta_{\rho}$, per $1000 \mathrm{MW}$, is given by

$$
\Delta_{\rho}=a_{1} e^{-b_{1} l_{D}} \tan \rho
$$

If one assumes a " $\mathrm{T}$ " configuration for the diffuser, then the diameter of each of the two diffuser sections can be approximated by 0.707 of the discharge conduit diameter. ${ }^{17}$

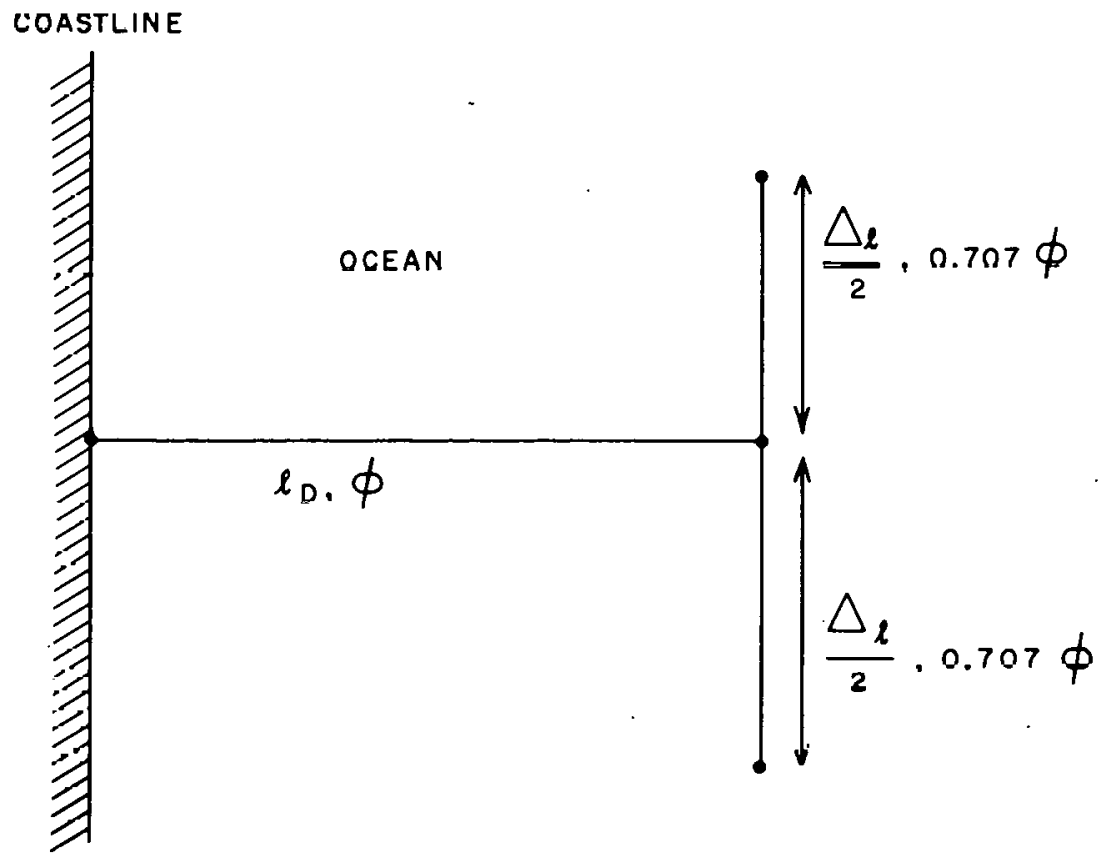

Figure 6. Definition of $\Delta_{\ell}$. 
The diffuser length for a system of $g$ GW of electrical capacity is thus

$$
\ell_{D}=g \quad a_{1} e^{-b_{1} \ell_{D}} \tan \rho
$$

If the cost per $f t$. of diffuser pipe per $f t$. of diameter is $\Omega_{4}$, then the total cost for the diffuser system is

$$
\mathrm{g} \quad \mathrm{a}_{1} \mathrm{e}^{-\mathrm{b}_{1} \ell_{\mathrm{D}} \tan \rho \cdot 0.707 \phi \Omega_{4}}
$$

If one adds the cost of the conduit from the coastline to the diffuser location, the total system cost is

$$
C_{D F}=0.707 \phi \Omega_{4} g a_{1} e^{-b_{1} \ell_{D} \tan \rho}+\ell_{D} k_{1} \phi^{\beta} \text { ENR }
$$

For given $\phi$ the optimum value of $\ell_{D}$, say $l_{D}{ }^{*}$, is given by the solution to

$$
\frac{\mathrm{dC}_{\mathrm{DF}}}{\mathrm{d}_{\mathrm{D}}}=0
$$

hence $\ell_{D}^{*}$ is given by the solution to

$$
0=.707 \phi \Omega_{4} \mathrm{gaa}_{1}{ }^{-\mathrm{b}_{1} \tan \rho} \mathrm{e}^{-\mathrm{b}_{1} \ell_{\mathrm{D}}{ }^{*} \tan \rho}+\mathrm{k}_{1}{ }^{\beta}{ }^{\beta} \mathrm{ENR}
$$

from which

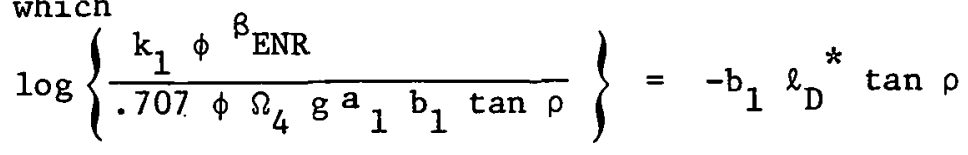

and thus

$$
\ell_{D}^{*}=\frac{\log \left\{\frac{k_{1} \phi^{\beta}}{.707 \phi \Omega_{4} g a_{1} b_{1} \tan \rho}\right\}}{-b_{1} \tan \rho}
$$

The system cost corresponding to this optimum value is then obtained by inserting $\ell_{D}^{*}$ into Eq. (22). 
1. The assistance of Dr. D. McCreath, of Acres American, Inc., is gratefully acknowledged.

2. See e.g., F.T. Wheby, and E.M. Cikanck, "A Complete Program for Estimating Costs of Tunnelling (COSTUN)" Published by NTIS, Report PB 229 865/1 WX, and PB 228 740/7WX, Oct. 1973.

3. C.T. Brandt, et al., "A Systems Study of Soft Ground Tunnelling" Felix and Scisson, Inc., Tulsa, Oklahoma, May 1970, Published by NTIS, PB 194769 .

4. All cost estimates were adjusted to 1973 dollars.

3. The addition of tunnel length $\ell$, in $1000 \mathrm{ft}$, into the regression increased the proportion of variance explained to 57 percent. The augmented equation was

$$
y=4.00 \phi^{2.03} \ell^{-.2333}
$$

As expected, longer tunnels decreased the unit costs. However, in view of the ambiguity in defining tunnel length in our application (would, for example, intake and discharge conduits count as one or as two tunnels?), the simpler dependency of cost on diameter alone was used in the mathematical model.

6. Note that the volume of excavated material, $v_{e}$, for a tunnel of length $\ell$, of interest in terms of assessing environmental impact, is given by

$$
\mathrm{V}_{\mathrm{e}}=\frac{\pi}{21} \ell\left(\frac{\phi_{\mathrm{O}}}{\dot{2}}\right)^{2}=0.785 \ell(1+\tau)^{2} \phi^{2}
$$

7. N.A. Christensen "Aqueducts for least cost conveyance of Water" Journal, Irrigation and Drainage Division, ASCE, Vol. 97 1R3, Sept. 1971 (p. 483).

8. See, e.g., H.W. King and E.F. Brater, "Handbook of Hydraulics", 5th Edition, 1963, McGraw-H1ll, New York, p. 6-14.

9. North Atlantic Regional Water Resources Study, Appendix R, Water Supply, p. R-14.

10. Ib1d. 
11. See, e.g. Final Environmental Statement, Limerick Generating Station, Units 1 and 2, U.S. AEC, Directorate of Licensing, Nov. 1973, Comments of the Delaware River Basin Commission, p. H-26. For further discussion of the storage-yield relationship for Northeastern River Basins, see J. Edinger, "Water Resource Constraints on Power Facility Siting in the Northeast", BNL Regional Energy Studies Program, Forthcoming Report.

12. See NEC-NECSS, Vo1. III, Table 3.15, section 3.3.7.2.1.

13. Ibid.

14. Ibid.

15. For an excellent review of the State-of-the-art of analytical modelling of thermal discharges, see B.A. Benedict, J.L. Anderson and E.L. Yandell "Analytical Modelling of Thermal Discharges" Argonne National Laboratory, Report ANS/ES-18, April 1974.

16. B. Brodfeld "Engineering and Cost Considerations in meeting thermal discharge criteria", Stone and Webster Engineering Corporation, 1973.

17. If one assumes that the flow velocity in each section immediately after bifurcation $V$ must equal the velocity in the main stem immediately before bifurcation, $V_{y}$, then if $Q_{x}, Q_{y}$ denote flows

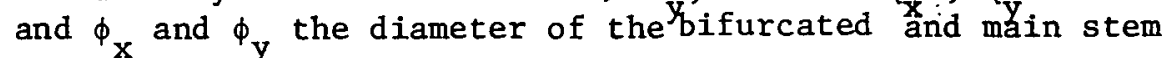
sections respectively.

$$
v_{x}=\frac{4 Q_{x}}{\pi \phi_{x}^{2}}=v_{y}=\frac{4 Q_{y}}{\pi \phi_{y}^{2}}
$$

But since $Q_{x}=0.5 Q_{y}$

$$
\frac{0.5 Q_{y}}{\phi_{x}^{2}}=\frac{Q_{y}}{\phi_{y}^{2}}
$$

or

$$
\phi_{x}^{2}=0.5 \phi_{y}^{2}
$$

and

$$
\phi_{x}=0.707 \phi_{y} \text { Q.E.D. }
$$

'This analysis ignores fraction lossess associated with sudden contractions of flow cross sections or the bifurcation fitting (See e.g., L.G. Kich "Unit Uperations of Sanitary Engineering," Wiley, New York, 1961, p. 14). 
THIS PAGE

\section{WAS INTENTIONALLY LEFT BLANK}




\subsection{Introduction}

Because the multi-period model proves to be quite complex, we shall introduce the basic features of the optimization model using a singletime period formulation, using minimization of total annual cost as the optimization criterion. For given choice of cooling system and given location, the major determinant of total system cost will be the number and diameter of conduits; and thus the determination of these two variables is the basic purpose of the analysis. The latter variable is obtained by differentiation of the total cost function with respect to diameter; and the former by enumeration. Because the number of conduits for even a large NEC has only a few alternatives, enumeration proves to be the most efficient procedure.

In the following discussion, we shall use the term "conduit" to encompass both intake and discharge pipe. Thus, for example, an NEC served by 5 "conduits" (one conduit for each reactor quad) would in fact require 5 intake pipes, and 5 discharge pipes. Figure 7 illustrates the definition of the various pipe lengths. We shall also assume the use of tunnels, as would be the case at the Ocean County NEC; the computer program, however, is written in such a way as to allow specification of surface conduits, if desired. In that event, the tunnel cost functions are replaced by the functions derived in section 2.6 and only minor changes to the optimization expressions derived in this Chapter are required. ${ }^{1}$

\subsection{Once-through systems}

In a once-through cooled system, intake and discharge conduits carry the same quantity of water, and we can assume that for each conduit the length of tunnel is $L_{T}=2 \ell^{\prime}+\ell^{\prime}{ }_{I}+\ell^{\prime}{ }_{D}$ (See Figure 5). Moreover, since the energy required for static head in the intake is 


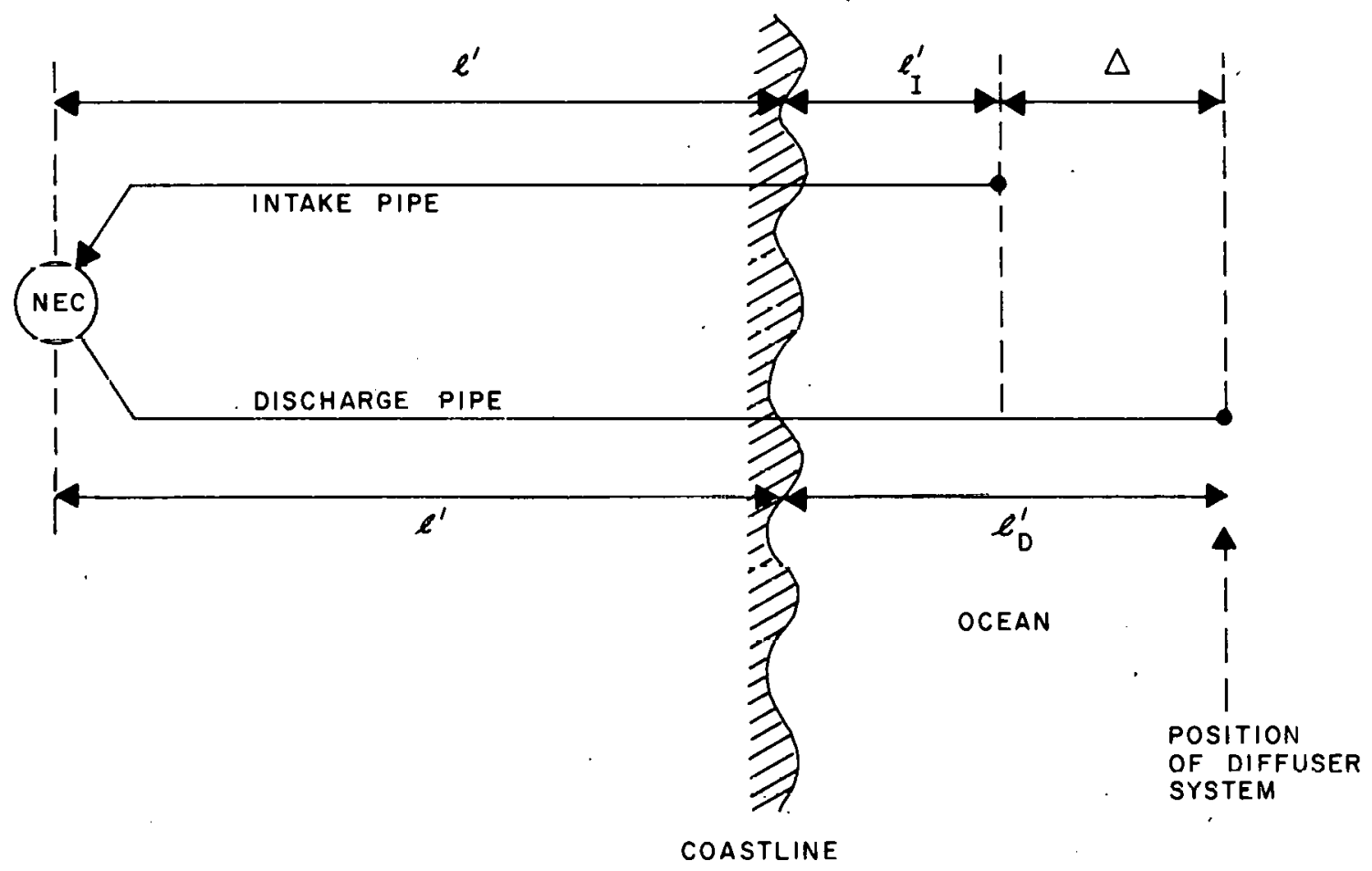

TUTAL LENGTH OF TUNNELS $=\mathrm{L}_{\mathrm{T}}=2 \ell^{\prime}+\ell_{\mathrm{I}}^{\prime}+\ell_{\mathrm{D}}^{\prime}$ PER CONDUIT

Figure 7. Definition of conduit lengths. 
regained in the outfall, we note that the total pumping head is

$$
\begin{aligned}
h_{T} & =h_{f} \text { (intake) }+h_{S} \text { (intake) }+h_{f} \text { (discharge) }-h_{s} \text { (discharge) } \\
& =h_{f} \text { (intake) }+h_{f} \text { (discharge) }
\end{aligned}
$$

and we can thus ignore the pumping energy costs for static head. It follows that for a system of $M$ conduits, the total annual cost is given by the expression

$$
\begin{aligned}
& C_{1}=M \cdot \operatorname{CRF}(i, j)\left\{\begin{array}{c}
L_{T} \cdot \operatorname{ENR} \cdot k_{1} \phi^{2.15}+\operatorname{ENR~} k_{2}\left(\frac{Q}{M}\right)^{0.3} \\
\text { tunnels }
\end{array}\right.
\end{aligned}
$$

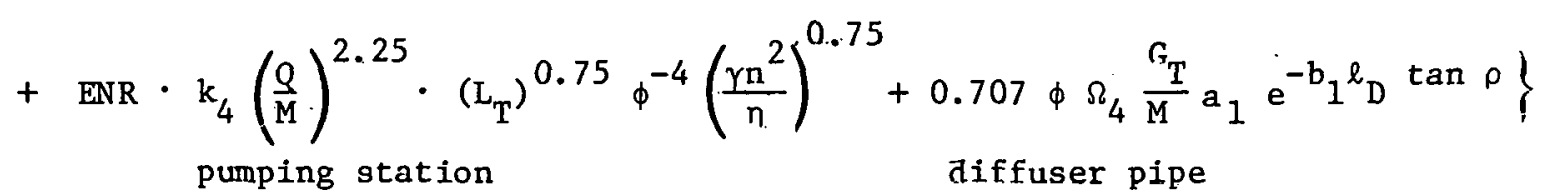

$$
\begin{aligned}
& +M 55.23 \alpha\left(\frac{Q}{M}\right)^{3} \frac{\gamma n^{2}}{\eta} \cdot L_{T} \phi^{-5.333} \\
& \text { pumping energy cost }
\end{aligned}
$$

For given $M$, this function can be differentiated with respect to $\phi$ to find the optimum diameter, thus

$$
\begin{aligned}
\frac{\partial C_{1}}{\partial \phi}=0 & =\operatorname{CRF}(i, j) \cdot M \cdot \operatorname{ENR} \cdot 2.15 k_{1} L_{T} \phi 1.15 \\
& =\operatorname{CRF}(i, j) \cdot M \cdot \operatorname{ENR} 4 k_{4}\left(\frac{Q}{M}\right)^{2.25} L_{T} 0.75 \phi^{-5}\left(\frac{\gamma n^{2}}{\eta}\right)^{0.75} \\
& +\operatorname{CRF}(1, j) 0.707 \Omega_{4} G_{T}{ }^{2} e^{-b_{1} l_{D} \tan \rho} \\
& -M \cdot 55.23 \propto\left(\frac{Q}{M}\right)^{3} \cdot \frac{\gamma n^{2}}{\eta} L_{T} 5.33 \phi-6.33
\end{aligned}
$$

is set equal to zero and solved for the optimum diameter, $\phi^{*}(\mathrm{M})$. Note that from (24) the value of $\ell_{D}$ to be inserted into (26) is given by 


$$
l_{D}=\frac{\ln \left\{\frac{E N R k_{1} \phi^{\beta} M}{0.707 \phi \Omega{ }_{4} G_{T} a_{1} b_{1} \tan \rho}\right\}}{-b_{1} \tan \rho}
$$

In fact, (26) must be solved numerically since there is no explicit solution $\phi^{*}(M)$. However, Newton's method proves to be quite efficient for solution; for each trial value of $\phi$, one first computes (27) and inserts the value of $\ell_{D}$ into (26), until the correct value of $\phi$ (that satisfies (26)) is obtained. ${ }^{2}$ Having thus determined the optimal diameter for each $M$, we then determine the optimal $M$, denoted $M^{*}$, simply by substituting $\phi^{*}(M)$ Inco Eq. (25), and selecting that $M$ corresponding to

$$
\operatorname{Min}\left\{\mathrm{C}_{1}\left(\phi^{*}(\mathrm{M})\right)\right\}
$$

\subsection{Evaporat1ve Systems}

The evaporatively cooled system differs to the once-through cooled system in a number of respects. First, one may assume that no diffuser system will be needed, and hence those terms can be dropped. Second, the volume of makeup, (equal to the flow in the intake pipe) is greater than the volume of blowlown (the flow in the discharge pipe). In tact, if $Q$ denotes the makeup flow, and $Q_{B}$ the blowdown, ${ }^{3}$

$$
Q_{B}=\frac{Q}{N}
$$

where $N$ is the concentration factor. For the conditions defined in Table 1 , $\mathrm{N}=1.45$, hence

$$
\mathrm{Q}_{\mathrm{B}}=.689 \mathrm{Q}
$$

Since the flow in the discharge pipe is thus some $30 \%$ less than in the intake, it follows that the optimal diameters of intake and discharge pipes are not necessarily the same. Consequently, intake and discharge pipes must be separately optimized for the evaporative cooling case. ${ }^{4}$ We also introduce the following notation for total length of discharge and intake pipe (see Figure 5). 


$$
\begin{aligned}
& \ell_{D}=\ell^{\prime}+\ell_{D}^{\prime} \\
& \ell_{I}=\ell^{\prime}+\ell_{I}^{\prime}
\end{aligned}
$$

The total cost for the intake pipe is then given by

$$
\begin{aligned}
& C_{I}=\frac{11.881 \alpha Q \sigma h_{S}}{n}+M \quad 55.23 \alpha\left(\frac{Q}{M}\right)^{3} \frac{\gamma n^{2}}{\eta} e_{I} \phi^{-5.333} \\
& \text { pumping energy-static pumping energy-friction loss } \\
& +\mathrm{M} \operatorname{CRF}(i, j) \quad \operatorname{ENR} \mathrm{k}^{2.15} \phi^{1.15} \ell_{I}+0.5 \mathrm{MCRF}(i, j) \operatorname{ENR} \mathrm{k}_{2}\left(\frac{Q}{M}\right)^{0.3} \\
& \text { intake and tunnel construction } 50 \% \text { of intake-discharge } \\
& +M \quad \operatorname{CRF}(i, j) \text { ENR }\left\{k_{3}\left(\frac{Q h_{s} \sigma}{\eta}\right)^{0.75}+k_{4}\left(\frac{Q}{M}\right)^{2.25} l_{I}^{0.75} \phi^{-4}\left(\frac{\gamma n^{2}}{n}\right)^{0.75}\right\} \\
& \text { pumping station construction cost }
\end{aligned}
$$

Thus the optimal intake diameter, for given $M$, is given by setting

$$
\frac{\mathrm{dC}_{\mathrm{I}}}{\mathrm{d} \phi}=\dot{0}
$$

and solving for $\phi$. The optimal diameter, denoted $\phi_{I}^{*}(M)$, is in fact the root of ${ }^{4}$

$$
\begin{aligned}
y\left(\phi_{I}^{*}(M)\right) & =M \cdot \operatorname{CRF}(i, j) l_{I} \cdot \operatorname{ENR} \cdot k_{4} \cdot 2.15 \phi_{I}^{*}(M) 1.15 \\
& -M \cdot \operatorname{CRF}(i, j) \cdot \operatorname{ENR} \cdot k_{4} \cdot\left(\frac{Q}{M}\right)^{2.25} \ell_{I}^{0.75} \phi_{I}^{*}(M)^{-5}\left(\frac{\gamma n^{2}}{\eta}\right)^{0.75} \\
& -294.55 \cdot M \cdot \alpha\left(\frac{Q}{M}\right)^{3}\left(\frac{\gamma n^{2}}{\eta}\right) l_{I} \phi_{I}^{*}(M)
\end{aligned}
$$

Since the intake-discharge structure cost does not enter into this computation, the apportionment of the intake-discharge structure cost to intake and discharge is immaterial. 
For the discharge conduit, we are pumping downhill, and thus we replace Eq. (10) by

$$
H P=\frac{Q \alpha\left(h_{f}-h_{s}\right)}{\eta \cdot 550}
$$

from which it follows that for pumping station construction of the downhill discharge conduit, we need merely change the sign of $k_{3}$. Similarly, for pumping energy costs, we replace $h_{s}$ by $-h_{s}$.

The optimum discharge pipe diameter, $\phi_{D}^{*}(M)$, is then given by the root of

$$
\begin{aligned}
y\left(\phi_{D}^{*}(M)\right) & =M \cdot \operatorname{CRF}(i, j) \cdot \operatorname{ENR} \cdot k_{4}^{2.15} \phi_{D}^{*}(M)^{1.15} \ell_{D} \\
& -M \cdot \operatorname{CRF}(i, j) \cdot \operatorname{ENR} \cdot 4\left(\frac{\Omega}{N M}\right)^{2.25} \ell_{D}^{0.75} \cdot \phi_{D}^{*}(M)^{-5}\left(\frac{\gamma n^{2}}{n}\right)^{0.75} \\
& -M \cdot 294: 55 \alpha\left(\frac{Q}{N M}\right)^{3}\left(\frac{\gamma n}{n}\right) \ell_{n}^{2} \cdot \phi_{D}^{*}(M)
\end{aligned}
$$

On the assumption that the optimal number of conduits, $\mathrm{M}^{*}$, is the same for intake and discharge structures, the total water conveyance cost is

$$
\begin{aligned}
& =M^{*} \operatorname{CRF}(i, j) \text { ENR }\left\{\begin{array}{l}
\left\{k_{1} l_{I} \Phi_{I}^{*}\left(M^{*}\right)^{2.15}+k_{1}{ } D^{\phi}{ }^{*}\left(M^{*}\right)^{2.15}\right. \\
\text { intake tunnel discharge tunnel }
\end{array}\right. \\
& +k_{2}\left(\frac{Q}{M^{*}}\right)^{0.3}+k_{3}\left(\frac{Q h_{s}^{\sigma}}{n}\right)^{0.75}+k_{4}\left(\frac{Q}{M^{*}}\right)^{2.25} \ell_{I}^{0.75} \phi_{I}^{*}\left(M^{*}\right)\left(\frac{\gamma n^{2}}{n}\right)^{0.75} \\
& \text { intake-discharge structure intake pumping station } \\
& \left.+k_{4}\left(\frac{Q}{M^{*} j_{j}}\right)^{2.25} \ell_{D}^{0.75} \phi_{D}^{*}\left(M^{*}\right)\left(\frac{\gamma n^{2}}{n}\right)^{0.75}-k_{3}\left(\frac{Q h_{s} \sigma}{N_{n}}\right)^{0.75}\right\} \\
& \text { discharge pumping statinn } \\
& +M \cdot 55.23 \alpha\left(\frac{Q}{M}\right)^{3} \cdot \frac{\gamma n^{2}}{\eta} l_{I} \phi^{-5.333}+\frac{11.881 \alpha Q \sigma h_{s}}{\eta} \\
& \text { intake pumping energy }
\end{aligned}
$$




$$
\begin{gathered}
+M \cdot 55.23 \alpha\left(\frac{\Omega}{M N}\right)^{3} \frac{\gamma n^{2}}{n} \ell_{D} \phi^{-5.333}-\frac{11.881 \alpha Q \gamma h_{s}}{n N} \\
\text { discharge pumping energy }
\end{gathered}
$$

\subsection{Results}

Tables 2, 3, and 4 show the optimization results for the Ft. Dix, Inland, and Bay locations, respectively. As one might expect, the scale economies in construction and pumping costs result in a single conduit (i.e. one intake pipe and one discharge pipe) being the optimal configuration. In the evaporatively cooled cases (Ft. Dix and Inland), we note also that intake and discharge conduits are indeed of different diameter, but the optimal number of conduits is the same for both intake and discharge, as asserted in a previous section. 5

\subsection{The Constrained Problem}

- Inspection of Tables 2 and 3 for the evaporatively cooled NEC's shows the optimal diameter for $M>1$ to lie below $10 \mathrm{ft}$. For near-surface buried pipes, these values would be quite feasible, but a bored tunnel of less than $10 \mathrm{ft}$. diameter is not a feasible proposition. Consequently, one must impose an inequality constraint on the optimization problem, such that the optimal diameter be equal to or greater than some minimum diameter, assumed here to be $10 \mathrm{ft}$.

Intiuitively, the imposition of such a constraint on tunnel diameter would result in a somewhat higher tunnel construction cost, but, because friction losses in the now wider tunnel are less, somewhat lower pumping costs. Tables 5 and 6 , which show the computer simulation results for an assumed minimum tunnel diameter of $10 \mathrm{ft}$., show that this is indeed the case. For example, compare the results for $M=10$ as shown on Table 3 for the Inland NEC, with the results for $M=10$ on Table 6 . The increase in the intake tunnel diameter from $5.47 \mathrm{ft}$. to $10.00 \mathrm{ft}$. results in an increase in tunne1 construction cost from $\$ 88 \mathrm{~m}$ to $\$ 322 \mathrm{~m}$, a decrease in pumping station construction from $\$ 33.4 \mathrm{~m}$ to $\$ 13.6 \mathrm{~m}$ and a decrease in 
TAELE 2 SYSIEM CUSTS LSING HOHEU TUNAELS, FT.DIX

EVAPONATIVE COOLING SYSIEM

TMETA

HUSHAK EMEHOY COST,SIKUK

EAR-1NCEA

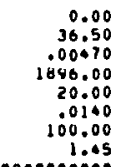

FUKCEU OUIAGE MATE

CAYIIAL AECOVEMY FACTUR

UELTA

PUMP EFFICIENCY

- INinup diane teki oft.

FULL OUTPUT

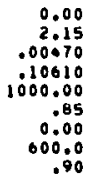

STATIC REAU,F',

.

aYERAGE AYATLe il ITY

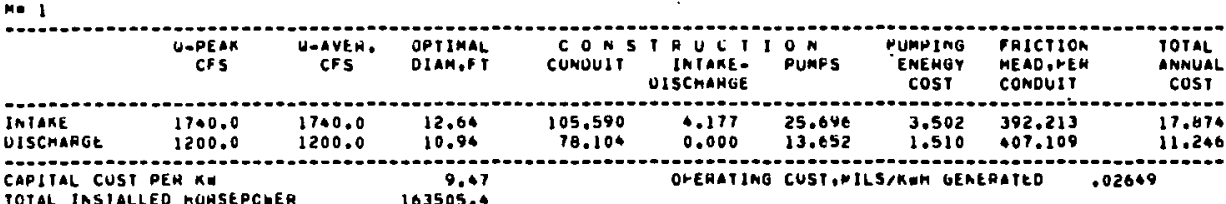

POTAL IASTALLED ROHSEPCHER

$n=2$

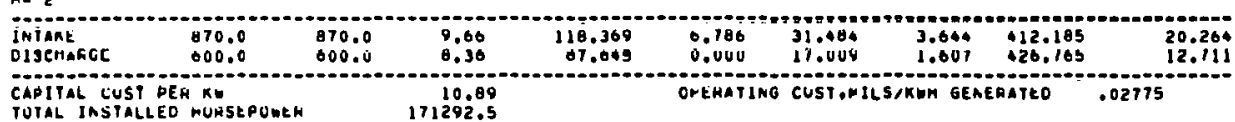

TOTAL IASTALLEO MURERPUER

171292.5

Ma 5

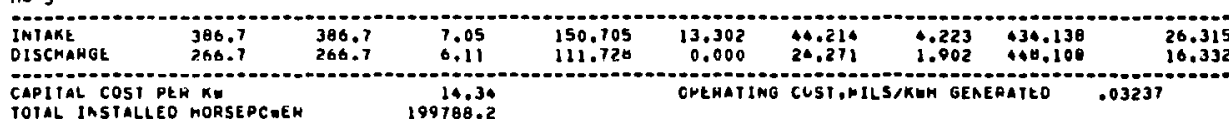

TOTAL IASTALLEO MORSEPCAEN

199788.2

$M=10$

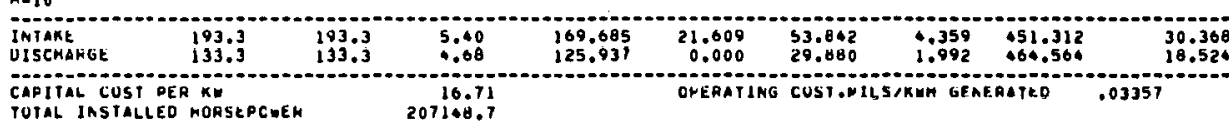

TOTAL INSTALLED MORSEPCUEN

207140.7

M-20

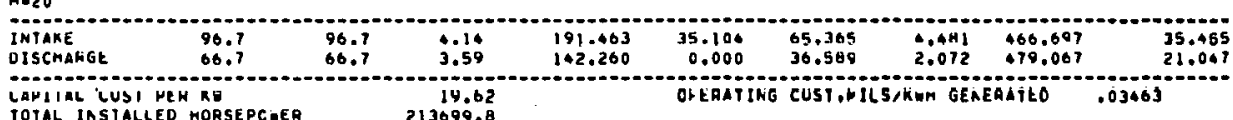

LAPIIRL LUSI MEH RE

213699.8 
TAELE 3 SYSIEM COSTS LSING BOMEU TUNNELS, INLANU

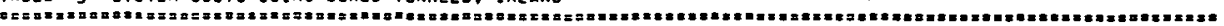

EVApOHative COOLING SYSTEM

THETA

SCMEDULEO MAINENANCE VUYYSTY

OUSHAN ENERGT COSTOSIKMH

EAR-INELX
AUE.OISTANCE 10 OCEAR,MILE

STATICA CUEFFICIENT

COAEENIMATICA FaCTUG, in

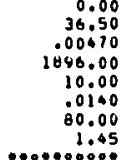

FOHCEU OUIAGE HATE

CONUUIT SCALE PACTOK

SYSTEF ENEHOY CCSI,ST/RWH

DELIA

PUAP EFFICIENCY

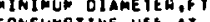

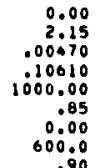

$H=1$

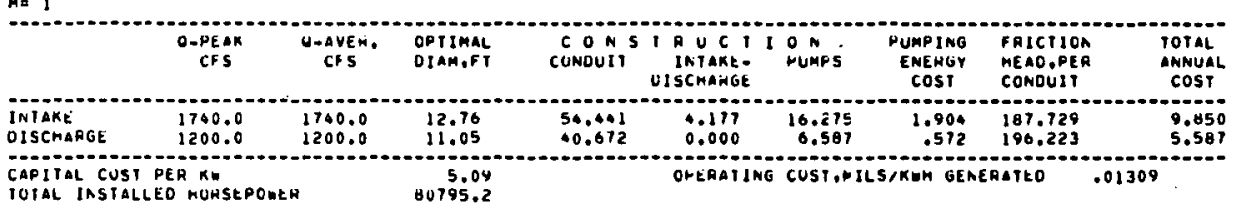

$M=2$

\begin{tabular}{|c|c|c|c|c|c|c|c|c|c|}
\hline $\begin{array}{l}\text { INIAKE } \\
\text { DISCHAFGE }\end{array}$ & $\begin{array}{l}070.0 \\
600.0\end{array}$ & $\begin{array}{l}870.0 \\
6000.0\end{array}$ & $\begin{array}{l}9.76 \\
8.06\end{array}$ & $\begin{array}{r}61.160 \\
45.740\end{array}$ & $\begin{array}{l}6.786 \\
0.000\end{array}$ & $\begin{array}{r}19.811 \\
8.250\end{array}$ & $\begin{array}{l}1.964 \\
.613\end{array}$ & $\begin{array}{l}196.105 \\
204.535\end{array}$ & $\begin{array}{r}11.276 \\
6.342\end{array}$ \\
\hline $\begin{array}{l}\text { PITAL } C \\
\text { PAL INS }\end{array}$ & nONSER & & $\begin{array}{r}5.9 \\
84090^{\circ} .\end{array}$ & & OHER & $S T, \ldots$ & WN & AATEO & \\
\hline
\end{tabular}

TOTAL IASTALLED HORSEPCLER

84090.3

$M=5$

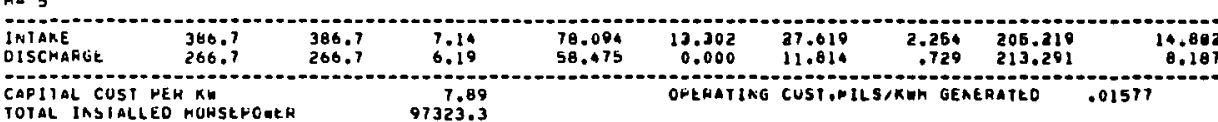

TOTAL InSIALLEO MUHSEVOAER 97323.3

ME 10

\begin{tabular}{|c|c|c|c|c|c|c|c|c|c|}
\hline $\begin{array}{l}\text { INTAKE } \\
\text { OISCMAFGE }\end{array}$ & $\begin{array}{l}193.3 \\
133.3\end{array}$ & $\begin{array}{l}193.3 \\
133.3\end{array}$ & $\begin{array}{l}5.47 \\
4.75\end{array}$ & $\begin{array}{l}88.144 \\
66.073\end{array}$ & $\begin{array}{r}21.004 \\
0.000\end{array}$ & $\begin{array}{l}33.0133 \\
14.500\end{array}$ & $\begin{array}{r}2.300 \\
.705\end{array}$ & $\begin{array}{l}212.051 \\
219.797\end{array}$ & $\begin{array}{r}17.500 \\
9.320\end{array}$ \\
\hline TOTAL IAS & NUWSED & & & & OLERA I & cus1, & & ARTED & \\
\hline
\end{tabular}

TOTAL IASTALLEO HULSEPCEER 1002

$m=20$

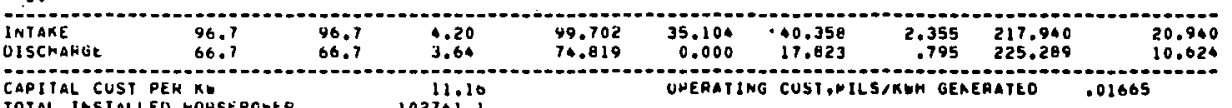

TOTAL INSTALLE MOHSEPONER

102711.1

UHERATING CUSi,piLs/KMH GEAERATLO 
TABLE 4 SYSTEM COSIS USINO BOREU TUNNELS, HAY

\begin{tabular}{|c|c|c|c|}
\hline 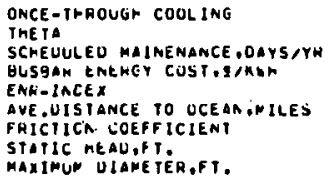 & $\begin{array}{r}0.00 \\
36.50 \\
.00670 \\
1806.00 \\
5.00 \\
.0100 \\
5.00 \\
5.0 .0\end{array}$ & 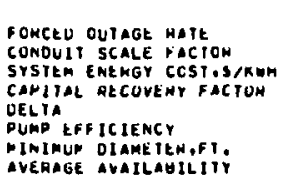 & $\begin{array}{r}0.00 \\
2.15 \\
.00 \$ 10 \\
110610 \\
1000.00 \\
.85 \\
0.00 \\
.90\end{array}$ \\
\hline
\end{tabular}

me

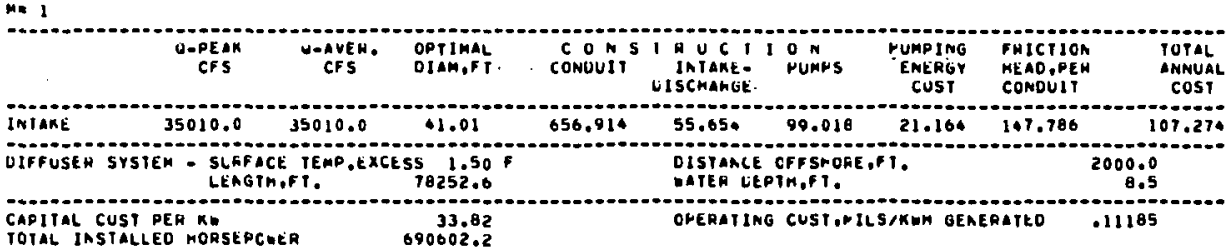

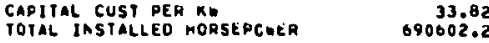

M. 2

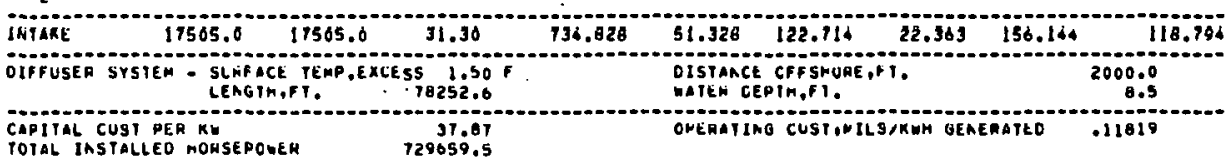

$M=5$

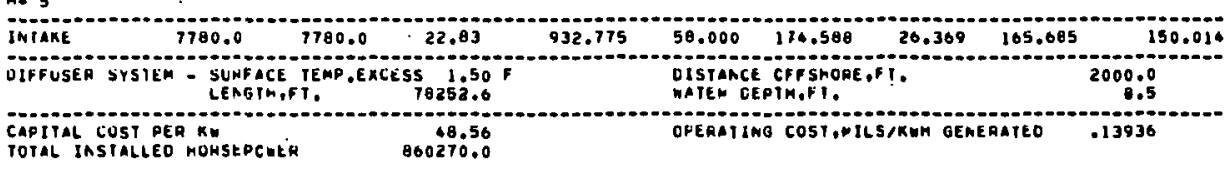

$M=10$

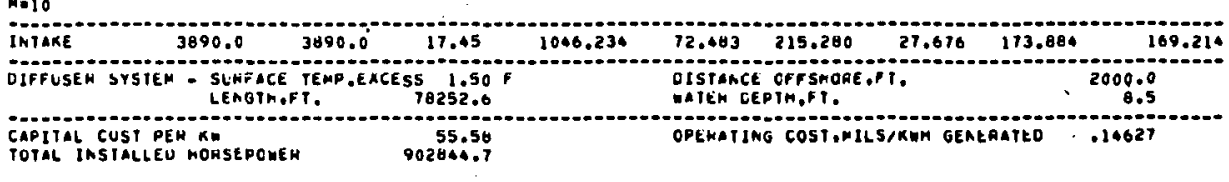

$M=20$

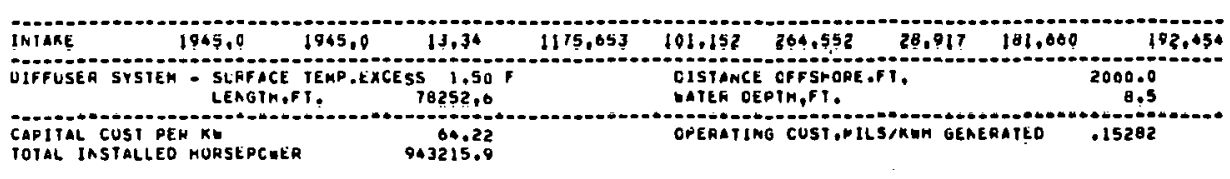


TABLE 5 SYSTEM COSTS USING GOHEO TUNNELS, FT,DIX

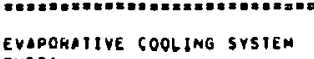
THETA SCHEUULEU MAINENANCE, DAYS/YA UUSBAR ENEAGY COST, SIKMM ENR - INOEX

STANCE TO OCEAR, WLES FAICIICA CUEFFICIENT STATIC HEAD,F MAXIMUM UIAMETEH, FT.

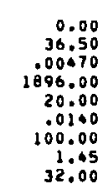

COHGE oUTAge hate CONOUIT SCALE FACTON SYSTER EAEHOY COST II/KWH

CAPITA

DELIA EFICIENCY

minimur ojame TER, Et.

COMSUPPIIVE USE AT FULL OUTPUT

avenage avallaulititi

0.00
2.15
.00670
.10610
1000.00
0.85
10.00
600.00
.90

m. 1

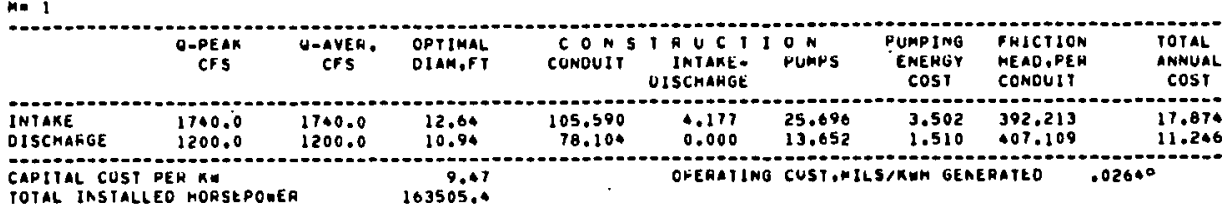

$M=2$

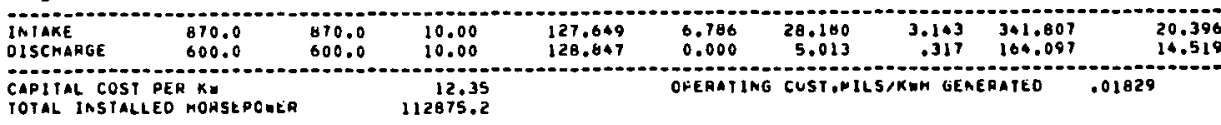

$m=5$

INIANE

$\begin{array}{llllllllll}\text { INIAKE } & 386.7 & 386.7 & 10.00 & 319.123 & 13.302 & 18.530 & 1.322 & 67.517 & 38.55 \\ \text { OISCHERGE } & 266.7 & 260.7 & 10.00 & 322.116 & 0.000 & 0.000 & 0.000 & 32.414 & 34.177\end{array}$

CAPITAL COST PER KA

TOTAL INSIALLE mOHSEPCIER

$M=10$

INTAKE

\begin{tabular}{|c|c|c|c|c|c|c|c|c|}
\hline $\begin{array}{l}\text { INTAKE } \\
\text { OISCHAFGE }\end{array}$ & $\begin{array}{l}193.3 \\
133.3\end{array}$ & $\begin{array}{l}193.3 \\
133.3\end{array}$ & $\begin{array}{l}10.00 \\
10.00\end{array}$ & $\begin{array}{l}630.205 \\
644.233\end{array}$ & $\begin{array}{r}21.600 \\
0.000\end{array}$ & $\begin{array}{r}16.822 \\
0.000\end{array}$ & $\begin{array}{r}.92 \\
0.00\end{array}$ & $\begin{array}{r}16.879 \\
8.104\end{array}$ \\
\hline
\end{tabular}

CAPITAL CUST WEK K

TCTAL InSIALLEO morstpoato

55.04

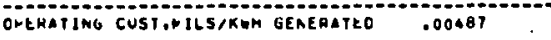

$M=20$

\begin{tabular}{|c|c|c|c|c|c|c|c|c|c|}
\hline $\begin{array}{l}\text { INTAKE } \\
\text { OISCHARGL }\end{array}$ & $\begin{array}{l}90.7 \\
66.7\end{array}$ & $\begin{array}{l}96.7 \\
66.7\end{array}$ & $\begin{array}{l}10.00 \\
10.00\end{array}$ & $\begin{array}{l}1276.491 \\
1280.465\end{array}$ & $\begin{array}{r}35.100 \\
0.000\end{array}$ & $\begin{array}{r}18.357 \\
0.000\end{array}$ & $\begin{array}{r}.021 \\
0.000\end{array}$ & $\begin{array}{r}4.220 \\
2.026\end{array}$ & $\begin{array}{l}101.929 \\
136.700\end{array}$ \\
\hline $\begin{array}{l}\text { CAPIIIAL CU } \\
\text { TOTAL IAST }\end{array}$ & KOHSEP & & $\begin{array}{r}109.10 \\
26894.3\end{array}$ & & OPERAT & $\cos 1$. & KWM GEN & $1 \in 0$ & \\
\hline
\end{tabular}


TABLE 6 STSTEM COSIS USING HOHEO TUNNELS, IMLARU

EVAPUNATIVE COOLING SYSTEM

IHETA

SCMEUULE DAIMENANCE DOYS/YH

SCHEVUL ENE
EUSR-INOEX

ENR-INDEX

FAE DISTANCE CUEF FICIENY

STOTIC MEAU .FT

SOACEATRATICA BACTOA, N

maximul DIAMETEK, F?

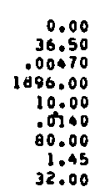

ponceu outage hate

CONJUII SCaLE Hicton

SVSTEm ENEar costos/atu

OELTA

Plin EFriciency

USE AT FULL OUTPUT

aveage avaILAGiLIT

m. 1

$\begin{gathered}\text { ME } \\ \text { O-PLAK } \\ \text { CIS }\end{gathered}$
U-AVER.
CFS

M. 2

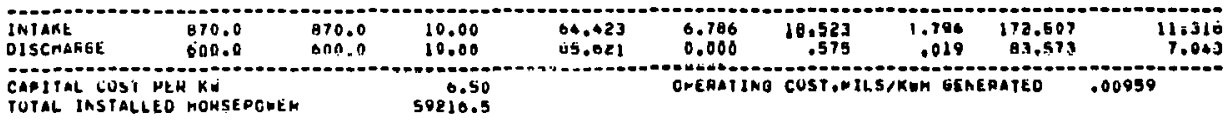

M. 5

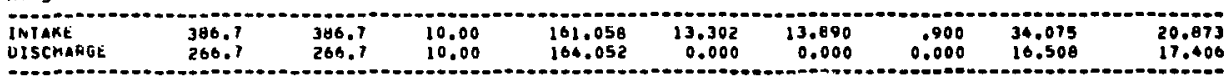
CAPITAL CUST DFo KK

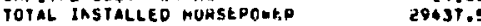

Malo

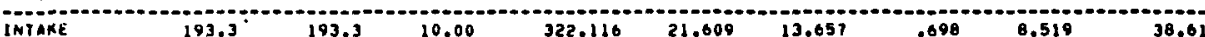

$\begin{array}{llllllllll}\text { INTAKE } & 193.3 & 193.3 & 10.00 & 322.116 & 21.609 & 13.657 & .698 & 0.519 & 38.616 \\ \text { OISCHARGE } & 133.3 & 133.3 & 10.00 & 328.100 & 0.000 & 0.000 & 0.000 & \$ .127 & 34.012\end{array}$
CAPITAL cosi PEA Ko TOTAL IASTALLEO MONSEPCUEH

$M=20$

INTAKE

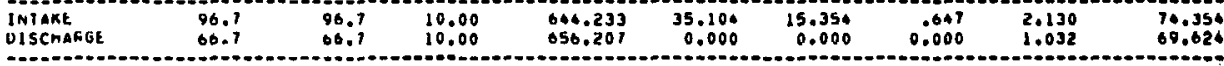

Capital cusi pery

TOTAL INSTALLEU nUHSEPOHEM

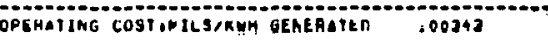

56,29
21103.9 
IABLE 7 SYSTEM COSIS USING GOREU TUNAELS, WAY

ONCE-TRROUGH COOLING

ONCE

THE TA

BUSBAH ENEFGY COST , \$/KOH

ENA-INOEX

AVE UISTANCE TO OCEANoPILES

FHICIION COEFFICIEN

STATIC MEAU,H

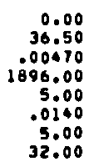

CORCEU OUTAGE HATE

SYSTEM ENERGY CCST, ST/M CAPITAL AE COVEAT FACTUR

DELTA

PUMP EFFICIENCY

MINIMUN UIAME IER, FI

.00470

.1061

10.00

nes 1

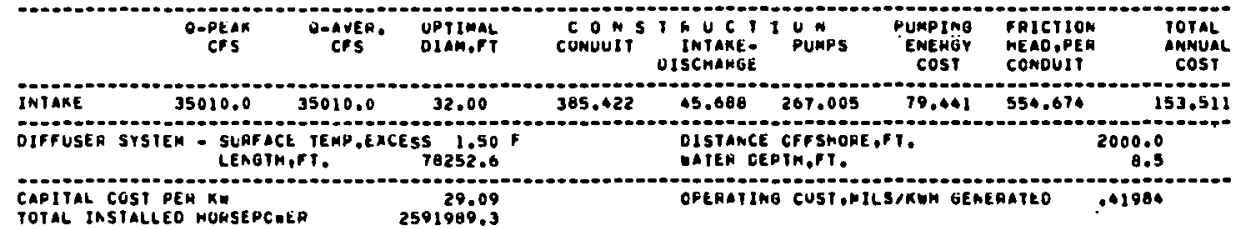

M. 2

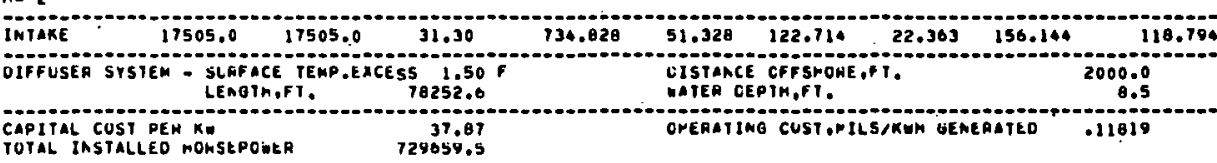

$M=5$

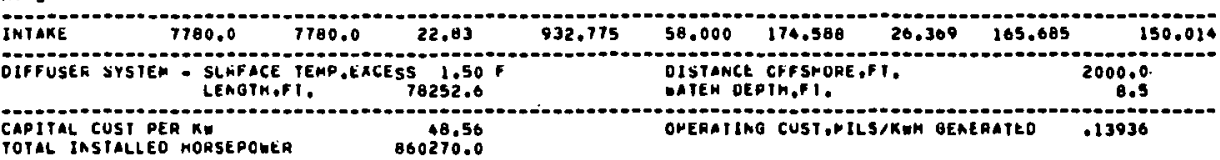

$M=10$

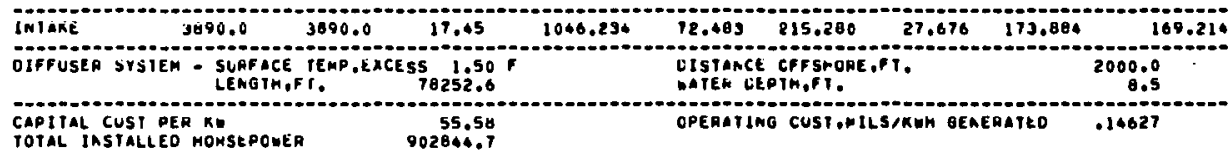

$M=20$

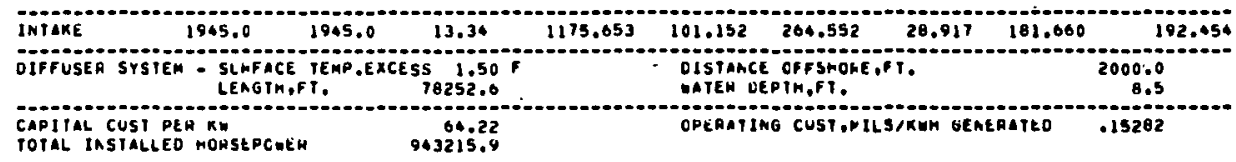


yearly pumping energy costs of $\$ 2.3 \mathrm{~m}$ to $\$ .7 \mathrm{~m}$, with the total annual cost increasing from $\$ 17.5 \mathrm{~m}$ to $\$ 38.6 \mathrm{~m}$.

An entirely similar situation exists with respect to maximum tunnel size, which, for soft ground tunnels of the type likely for the New Jersey Coastal Plain, would be around 30-35 ft. diameter. If one imposes, say, a $32 \mathrm{ft}$. diameter upper bound, the results for once-through cooling are significantly affected; the $41 \mathrm{ft}$. tunnel of Table 4 becomes a $32 \mathrm{ft}$. tunnel for the constrained optimum of Table 7. In this case, we note also that the optimum has shifted from a single conduit in the inconstrained case to two conduits for the constrained case; obviously, forcing all the water into a smaller than optimal size in the $M=1$ case implies a substantial increase in pumping station cost (due to implied increases in veolcity and friction losses). Comparison of Tables 4 and 7 for the $M=1$ case shows that pumping station construction costs do indeed rise, from $\$ 99 \mathrm{~m}$ in the $41 \mathrm{ft}$. unconstrained optimum diameter case (Table 4) to $\$ 267 \mathrm{~m}$ in the $32 \mathrm{ft}$. diameter constrained case (Table 7).

Computationally, incorporation of the constrained case requires little additional effort. If the computed unconstrained optimum diameter falls below $10 \mathrm{ft}$., (or whatever lower limit is inserted), that limit replaces the computed value in subsequent computation. Similarly, if the computed value falls higher than the upper limit, that upper limit is used subsequently. In fact, one can readily show that the optimum to the constrained problem is consistent with this apparently rather simple expedient.

Following the analysis of Meier, ${ }^{7}$. the Lagrange function for the constrained optimization problem can be stated as

$$
\mathrm{F}(\phi, \lambda, w)=\mathrm{f}(\phi)+\lambda_{1}\left(-\phi+\mathrm{w}_{1}^{2}+\phi_{\min }\right)+\lambda_{2}\left(\phi+\mathrm{w}_{2}{ }^{2}-\phi_{\max }\right)
$$

where $\phi_{\min }$ is the minimum conduit diameter; $\omega_{1}{ }^{2}$ is the slack variable corresponding to the inequality constraint $\phi \geq \phi_{\min }$, or $\phi-\omega_{1}^{2}=\phi_{\min }$; 
$\phi_{\max }$ is the maximum pipe diameter; $\omega_{2}{ }^{2}$ is the slack variable corresponding to the inequality constraint $\phi \leq \phi_{\max }$, or $\phi+\omega_{2}{ }^{2}=\phi_{\max } ; \mathrm{f}(\phi)$ is the cost function for the unconstrained problem, for example Eq (25) or (28); and $\lambda_{1}$ and $\lambda_{2}$ are the Lagrange multipliers. The corresponding Kuhn-Tucker conditions necessary for a minimum can be stated as ${ }^{8}$.

$$
\begin{aligned}
& \frac{\partial \mathrm{F}\left(\phi, \lambda_{1}, \lambda_{2}, \omega_{1}{ }^{2}, \omega_{2}{ }^{2}\right)}{\alpha \phi}=0=\frac{\partial F(\phi)}{\partial \phi}+\lambda_{1}+\lambda_{2} \\
& \lambda_{1}, \lambda_{2} \geq 0 \\
& \lambda_{1}\left(-\phi+\phi_{\min }\right)=0 \\
& \lambda_{2}\left(\phi-\phi_{\max }\right)=0
\end{aligned}
$$

This system can be seen to have 3 solutions:

1. $\lambda_{1}=\lambda_{2}=0 ; \phi_{\min }<\phi<\phi_{\max }$; which yields the same value for $\phi$ as in the unconstrained problem.

2. $\lambda_{1}>0 ; \lambda_{2}=0 ; \phi=\phi_{\min }$; corresponding to the lower bound on pipe diameter, and

3. $\lambda_{1}=0 ; \lambda_{2}>0 ; \phi=\phi_{\max } ;$ corresponding to the upper bound on pipe diameter.

Unless otherwise noted, all subsequent computations in this report impose Llie constraint $10 \lessdot \phi \lessdot 32$ for soft grnund t.unnels. 
1. The computer program is documented in a separate report - P.M. Meier "NECWSO-A Computer Code for Water Conveyance System Optimization: User Manual and Documentation" Regional Energy Studies Program, Brookhaven National Laboratory, forthcoming report.

2. Newton's Method has quadratic convergence properties (See e.g. C. Froberg "Introduction to Numerical Analysis", Addison-Wesley, Reading, Mass., 1964, p. 21) and computational experience with the solution to Eq. (26) indicates that a starting value of $\phi_{1}=1$ will result in convergence to \pm 0.0001 within 6 to 10 iterations.

3. See e.g., NRC-NECSS, Section 3.2.2. 2 for a discussion on these relationships.

4. This assumption will be verified in latpr sertions.

5. This in fact also holds true for the subsequent evaluation in Chapter $V$ of the multi-time period case, using total present worth as the optimization criterion.

6. Indeed, the range of diameters in the cost survey upon which the tunnel cost function is based is about 10 to $35 \mathrm{ft}$. and thus Eq. has no statistical validity beyond this range.

7. P. Meier, "MBglichkeiten zur Technischen und Wirtschaftlichen Optimierung von Zweckverbunden", Monograph Series Wasser und Abwasser, No. 4, Schmidt Verlag, Bielefeld, Federal Republic of Germany, 1972.

8. See e.g., R. Gue and M. Thomas, "Mathematical Methods in Operations Research", MacMillan, London, 1968. 
CHAPTER IV

ELECTRICAL SYSTEM RELIABILITY AND WATER CONVEYANCE COST

\subsection{Scheduled Maintenance}

In the preceeding analysis, we have assumed that all of the reactors in the NEC would be operating simultaneously; and that if the water demand for a single reactor is given by $q \mathrm{cfs}$, then the average total demand of the NEC would be 20q. In reality, however, this condition is far from satisfied. Even under the most optimistic assumptions, the expected availability of a reactor is unlikely to exceed 80 percent, implying that the average quantity of water demanded is not $20 \mathrm{q}$, hut $20 \mathrm{q}$ times the availability rate. 1

Unfortunately, the computations necessary for inclusion of this feature, as we shall see in the subsequent discussion, prove to be quite complex. However, we shall also note that the impact of reactor outages on the water conveyance system, and the determination of its optimal configuration and operation, is sufficiently important to merit detailed analysis.

First, consider the impact of scheduled maintenance. If $\mathrm{Z}$ days of such maintenance are scheduled per year, then the number of reactor years of scheduled outage in a group of $\mathrm{K}$ reactors is simply $\frac{\mathrm{Z}}{365} \mathrm{~K}$; and if maintenance is spaced evenly throughout the year, ${ }^{2}$ the maximum number of reactors available in a group of $\mathrm{K}$, say $\mathrm{K}^{*}$, is obviously

$$
\mathrm{K}^{*}=\mathrm{K}-\left.\frac{\mathrm{ZK}}{365}\right|_{\mathrm{I}}
$$

where the division by 365 is an Integer division with roundnff. The minimum number of reactors available is also given by Eq (31) but with roundup. These rules are illustraled on Table 8 , which also shows the corresponding water demands. 
Table 8

Impact of Scheduled Maintenance on Water Demand

$(z=36.5$ days per year $)$

\begin{tabular}{ccc}
$\begin{array}{c}\text { Number } \\
\text { of Groups } \\
=\mathrm{M}\end{array}$ & \begin{tabular}{c}
$\begin{array}{c}\text { Reactors } \\
\text { per group } \\
=\mathrm{K}\end{array}$ \\
\cline { 2 - 3 }
\end{tabular} \\
\cline { 2 - 3 } & 1 & 20 \\
2 & 10 \\
5 & 4 \\
10 & 2 \\
& 20 & 1
\end{tabular}

Reactor-Years of

per group per year

Scheduled Maintenance Reactor-Year

Available
Reactor-Years
per group

18

1.

0.4

0.2

0.1
Minimum

demand

$18 Q$

3.6

1.8

0.9
$3 \mathrm{Q}$

30

Maximum

demand

$18 \mathrm{Q}$

90

$4 Q$

$2 Q$

1Q

0
$\psi_{S}(M)$

.9

.9

1.0

1.0

1.0 
We note that in large groups of reactors, scheduled maintenance reduces the maximum water dcmand; whereas in small groups, for which $\frac{\mathrm{K} . \mathrm{Z}}{365}<1$, the maximum demand is not reduced, because under this condition there will be certain days in each year when no scheduled maintenance takes place. For the widely used figure of $Z=36.5$ days/year, the potential reduction in water demand in a 20 unit $\mathrm{NEC}$ can be as high as $10 \%$, and the savings are obviously worth consideration. We shall denote the reduction of water demand due to scheduled maintenance as $\psi_{\mathrm{s}}$ (m).

\subsection{Forced Outages}

Consider next the impact of forced outage. If there are $M$ conduits in a 20 unit $\mathrm{NEC}$, there will be $\mathrm{K}=\frac{20}{\mathrm{M}}$ reactors per conduit. But due to scheduled maintenance, only $\overline{\mathrm{K}}=\psi_{\mathrm{s}}(\mathrm{m}) \cdot \frac{20}{\mathrm{M}}$ will be available at any time. Then, if the forced outage rate is $\omega^{3}$, and if failures are independent, ${ }^{4}$ the probability that $\mathrm{r}$ of $\overline{\mathrm{K}}$ units will be on forced outage is given by the binominal distribution ${ }^{5}$

$$
\mathbf{P}_{\mathbf{r}}\{\mathbf{r}, \overline{\mathrm{K}}\}=\left(\begin{array}{l}
\overline{\mathrm{K}} \\
\mathbf{r}
\end{array}\right) \omega^{\mathbf{r}}(1-\omega)^{\overline{\mathrm{K}}-\mathbf{r}}
$$

For example, in the case of 20 reactors per conduit, $M=1$, and hence $\overline{\mathrm{K}}=18$; and if $\mathrm{r}$ units are on outage, the flow on that day will be given by

$$
Q^{\prime}(r)=(18-r) \cdot \frac{Q \cdot x_{S}(1)}{18}
$$

where $Q$ is the total NEC water demand as defined on Table 1 . Then from these two equations (32) and (33), one can readily compute the flow-duration curve; it is obviously highly unlikely that all 18 reactors will be operating simultanenisly. For example, fur $w=.2$ the probability of such an event is 0.018 or 1 chance in $55 .^{5}$

We note at this point that even if the pumping station were designed to handle the peak flow (with no units on forced outage, thus equal to $\left.x_{s}(\mathrm{~m}) \cdot \mathrm{Q}\right)$, the pumping energy costs will be significantly lower than those assumed in the previous Chapter. For a once-through NEC; one would, therefore, 
need to revise Eq. (25) to reflect the probabilistic nature of the flow, and the fact that the average annual flow is only $Q \cdot \psi_{s}(m) \cdot(1-\omega)$ rather than $Q$. The optimal diameter $\phi^{*}(M)$ can be shown to be given by solution of:

$$
\begin{aligned}
& \frac{d C}{d \phi}=0=M \cdot \operatorname{CRF}(i, j)\left\{\operatorname{ENR} 2.15 k_{1} L_{T} \phi^{1.15}\right. \\
& + \text { ENR d } k_{1}\left(\frac{Q \psi_{s}(m)}{M}\right)^{2.25} L_{T}^{0.75} \phi^{-4}\left(\frac{\gamma^{2}}{\eta}\right)^{0.75} \\
& \left.+0.707 \Omega_{4} \frac{G_{T}}{M} a_{1} e^{-b_{1} l_{D}} \tan \rho\right\} \\
& -M .55 .23 \alpha \frac{\gamma^{2}}{\eta} L_{T} 5.333 \phi^{-6.333} \sum_{r=1} \operatorname{Tr}\left(\frac{U_{r}}{M}\right)^{3}
\end{aligned}
$$

where

$$
\begin{aligned}
& P_{r}=\left(\begin{array}{l}
\bar{K} \\
r
\end{array}\right) \omega^{r}(1-\omega)^{\bar{K}-j} \\
& Q_{r}=\frac{(\bar{K}-r)}{\bar{K}} Q x_{s}(m)
\end{aligned}
$$

The last term in Eq. (34) represents average pumping energy costs, as derived in the Appendix. The corresponding annual cost is

$$
\begin{aligned}
& =\operatorname{CKL}(1,1) \operatorname{MENR}\left\{L_{\mathrm{H}^{\prime}} k_{1} \phi^{2.15}+k_{\cdot 2}\left(\frac{Q x_{s}(\mathrm{~m})}{\mathrm{M}}\right)^{0.3}\right. \\
& \left.+k_{4}\left(\frac{0 x_{s}(m)}{M}\right)^{2.25} L_{T}^{0.75} \phi^{-4}\left(\frac{\gamma^{2}}{n}\right)^{0.75}\right\} \\
& +\quad 0.707 \delta_{4} \phi \frac{G_{T}}{M} a_{1} e^{-b_{1} l_{D} \tan \rho \cdot C R F(i, j) M} \\
& +294.55 \alpha \frac{\gamma n^{2}}{\eta} L_{T} \phi 5.333 \sum_{r=1}^{\overline{\mathrm{K}}} \mathrm{P}_{\mathrm{r}}{\frac{\mathrm{Q}_{\mathrm{r}}}{\mathrm{M}}}^{3}
\end{aligned}
$$

This lime of reasoning leads to some further possibilities of purposely underdesigning the water conveyance system. In the case of an evaporative 
cooled system, for example, this would result in temporary increases in concentration ratio (on such few days as no reactors are on forced outage, an inadequate volume of make-up would automatically result in a higher $\mathrm{N}$, and the resulting increases in rnrrosivencas, being cemporary, might be worth the capital cost saving of a slightly underdesigned water conveyance system). These possibilities are explored in more detail elsewhere. ${ }^{6}$

One might note that in this analysis we assume that a reactor not on scheduled maintenance or forced outage is in fact generating power at ful1 load; we thus ignore reserve shutdowns ${ }^{7}$ and the fact that output is not always at full capacity. ${ }^{8}$ To that extent, the results for water quantities demanded would be conservative. Thus, for purposes of this analysis, we define average availability as

$$
A=\left(\frac{365-Z}{365}\right)(1-\omega)
$$

\subsection{Results}

The impact of outages on the optimum water conveyance system design is illustrated on Tables 9, 10, and 11. We note that system costs do indeed fall as the forced outage rate $\omega$ increases and average availability decreases.

For the evaporatively cooled systems (Tables 9 and 10), we note savings up to $14 \%$ at the $\omega=0.3$ level, equivalent to an annua 1 saving of $\$ 2.5 \mathrm{~m}$ at the $\mathrm{Ft}$. Dix site. In the once-through case, the saving is even more dramatic; for $\omega=0.3$, equal to $\$ 50.5 \mathrm{~m}$ annually, a $33 \%$ saving over the base case computation that makes no allowances for outages. In a conduit of given size, pumping energy costs are proportional to the cube power of flow, (See Eq. (8)) and thus even small reductions in average flow have a significant impact when large quantities of water must be moved. This effect is especially pronounced when an upper bound on maximum conduit size forces the balance between condult costs and pumping costs into the direction of the latter, as is the case in the once-through system. here examined. 
Table 9

Impa=t of Outages on System Cost

Ft. Dix,$M=1$, Intake Conduit

\begin{tabular}{|c|c|c|c|}
\hline \multirow[b]{2}{*}{$\begin{array}{l}\text { No outage } \\
\text { A-justment }\end{array}$} & \multicolumn{3}{|c|}{ Average Availability } \\
\hline & $\begin{array}{c}0.81 \\
(\omega=0.1, \\
z=36.5) \\
\end{array}$ & $\begin{array}{c}0.72 \\
(\omega=0.2, \\
z=36.5)\end{array}$ & $\begin{array}{c}0.63 \\
(\omega=0.3, \\
z=36.5) \\
\end{array}$ \\
\hline 1933 & 1740 & 1740 & 1740 \\
\hline 1933 & 1392 & 1392 & 1218 \\
\hline 12.6 & 12.3 & 12.0 & 11.7 \\
\hline 105.6 & 100.0 & 94.7 & 89.9 \\
\hline 4.2 & 4.2 & 4.2 & 4.2 \\
\hline 25.7 & 27.8 & 30.2 & 32.8 \\
\hline 3.5 & 3.0 & 2.5 & 2.0 \\
\hline 17.9 & 17.0 & 16.2 & 15.4 \\
\hline 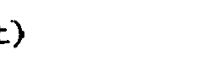 & $(=5 \%)$ & $(=9.5 \%)$ & $(=14 \%)$ \\
\hline
\end{tabular}

Peak Flow, cfs

Average Flow, cfs

Op=imal Diameter, $\mathrm{ft}$

Tune- constructicn cost, $x=0^{t}$.

Intake-dis sharge structure cost

Punpiag Station cost $\times 10^{6}$

10

Pumping Energy cost, per year,
\[ x 10^{6} \]

Tc.tal Annual cost

$(=5 \%)$

$(=9.5 \%)$

$(=14 \%)$ 
Table 10

\section{Impact of Outages on System Cost}

Inland, $M=1$, Intake Conduit

Average Avallability

\begin{tabular}{lccc} 
& 0.81 & 0.72 & 0.63 \\
No outage & $(\omega=0.1$, & $(\omega=0.2$, & $(\omega=0.3$, \\
adjustment & $z=36.5)$ & $z=36.5)$ & $\underline{z}=36.5)$ \\
\hline
\end{tabular}

Peak Flow, cfs

1933

$17 \dot{40}$

1740

1740

Average Flow, cfs

1933

1566

1392

1218

Optimal Diameter, $f t$

12.8

12.5

12.19

11.9

Tunnel construction cost, $\times 10^{6}$

54.4

51.8

49.3

47.0

Intake-discharge structure cost

Pumping station cost $\times 10^{6}$

4.2

4.2

4.2

4. 2

16.2

17.4

18.6

19.9

Pumping Energy cost, per year

1.9

1.6

9.5

1.3

1.1

Total Annual cost

9.9

$(=4 \%)$

9.0

8.6

Annual Saving (over zero outage cost)

$(=9 \%)$

$(=13 \%)$ 
Table 11

Impact of Outages on System Cost

Bay, $M=$

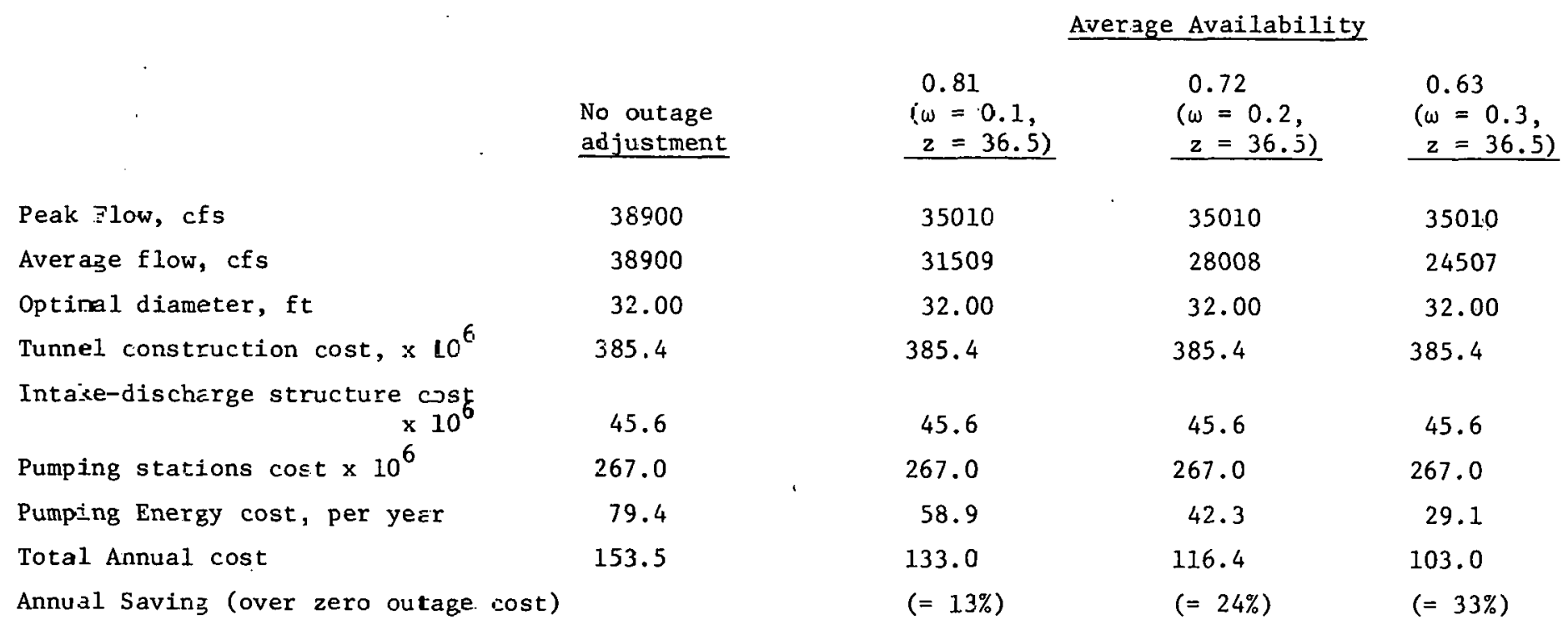




\section{APPENDIX: Derivation of Pumping Energy Costs for}

the Stochastic Case

The pumping horsepower requirement is derived in Chapter II (Eq. (10)), as

$$
\mathrm{HP}=\frac{\mathrm{Q} \sigma\left(\mathrm{h}_{\mathrm{s}}+\mathrm{h}_{\mathrm{f}}\right)}{\mathrm{n} 550}
$$

hence the pumping cost $\mathrm{C}$, is

$$
\begin{aligned}
\mathrm{C} & =\alpha 0.746\left(\frac{\mathrm{KW}}{\mathrm{HP}}\right) \times 365.24\left(\frac{\mathrm{hrs}}{\mathrm{yr}}\right) \mathrm{HP} \\
& =\frac{11.81 \alpha \sigma}{n} Q\left(\mathrm{~h}_{\mathrm{s}}+\mathrm{h}_{\mathrm{f}}\right)
\end{aligned}
$$

but from Eq. (4), the friction or dynamic head $h_{f}$, is

$$
\begin{aligned}
h_{f} & =\frac{2.87 n^{2} \ell 16 Q^{2}}{\phi^{4 / 3} \pi^{2} \phi^{4}} \\
& =\frac{4.65 n^{2} \ell Q^{2}}{\phi^{5.33}}
\end{aligned}
$$

hence, inserting Eq. (37) in Eq. (38), we obtain the pumping cost

$$
C=\frac{11.881 \alpha \sigma Q}{n}\left(h_{s}+\frac{4.65 n^{2} \ell Q^{2}}{\phi^{5.333}}\right)
$$

but $Q$ is a random variable, hence $C$ is also a random variable. Taking expectations, the expected value of cost is

$$
E\{C\}-\frac{11.881 \alpha \sigma h_{\varepsilon}}{n} E\{\dot{Q}\}+\frac{55.24 \alpha \sigma n^{2} \ell}{n \phi^{5.33}} E\left\{Q^{3}\right\}
$$

hence

$$
\begin{aligned}
E\{C\} & =\frac{11.881 \alpha \sigma h_{S}}{n} \sum_{r=1}^{\bar{K}} P_{r} \frac{Q_{r}}{M}+\frac{55.24 \alpha \sigma n^{2} \ell}{n \phi^{5.33}} \sum_{r=1}^{\bar{K}} P_{r}\left(\frac{Q_{r}}{M}\right)^{3} \\
& =\sum_{r=1}^{\bar{K}} P_{r}\left\{k^{\prime}\left(\frac{Q_{r}}{M}\right)^{3}+k^{\prime \prime} \frac{Q_{r}}{M}\right\}
\end{aligned}
$$


where $\quad \mathrm{k}^{\prime}=\frac{55.2 \alpha \sigma \mathrm{n}^{2} \ell}{\eta_{\phi}^{5.33}}$

$$
\begin{aligned}
& \mathrm{k}^{\prime \prime}=\frac{11.81^{\prime} \alpha \sigma \mathrm{h}_{\mathrm{s}}}{\eta} \\
& \mathrm{P}_{\mathrm{r}}=\left(\begin{array}{c}
\overline{\mathrm{K}} \\
\mathrm{r}
\end{array}\right) \omega^{\mathrm{r}}(1-\omega)^{\overline{\mathrm{K}}-\mathrm{r}} \\
& \mathrm{Q}_{\mathrm{r}}=\frac{\overline{\mathrm{K}}-\mathrm{r}}{\overline{\mathrm{K}}} Q \psi_{\mathrm{s}}(\mathrm{M})
\end{aligned}
$$

In the caoe of a onre-through conduit,

$$
E\{C\}=\sum_{r=1}^{\bar{K}} P_{r} k^{\prime}\left(\frac{Q_{r}}{M}\right)^{3}
$$

In the case of a discharge conduit in the evaporatively cooled case

$$
E\{C\}=\sum_{r=1}^{\cdot \vec{K}} P_{r}\left\{k^{\prime}\left(\frac{Q_{r}}{M}\right)^{3}-k^{\prime \prime}\left(\frac{Q_{r}}{M}\right)\right\} \delta_{r}
$$
where $\delta_{r}$ is defined as zero for any negative value of $\left\{k^{\prime}\left(\frac{Q_{r}}{M}\right)^{3}-k^{\prime \prime}\left(\frac{Q_{r}}{M}\right)\right\}$ unity
otherwise. This preyents the occurence of negative pumping energy custs, which might arise if the static head exceeds the friction head. 


\section{NOTES TO CHAPTER IV}

1. This point, although noted in our Preliminary Assessment, does not appear to have been considered in the main NRC study.

2. This assumption, to be sure, is a rather sweeping one. However, the subject of maintenance scheduling is extremely complex, with systemwide optimality of maintenance scheduling apparently only seldom achieved. As a working assumption for purposes of this discussion, however, the uniform maintenance assumption seems reasonable. If there were arguments based on existing practice that uniform scheduled maintenance was unlikely, the fact that we can show multi-million dollar yearly savings if such schedules were in fact adhered to should surely be considered. For further discussion the scheduled maintenance problem and particularly from the viewpoint of its relationship to system load-duration characteristics and system interconnection, see e.g. P. Meier, M. McCoy, and S. Rahman "A Perspective on the Energy Future of the Northeast: The Electric Sector" BNL 50553, Brookhaven National Laboratory, Sept. 1976.

3. The forced outage rate $\omega$ is defined as $\omega=\frac{\text { hours on forced outage }}{\text { hours on forced outage }+ \text { hours in service }}$

4. This assumption could well be questioned for the case of an NEC, where generating units may be closely connected electrically and for which the possibility of cascading outages would need to be more fully considered. However, the fact that reactors are grouped in a certain manner for water delivery does not imply that the same electrical connection would need to exist between them: moreover, the current thinking on the question of rellability is that reactors within an NEC would indeed not be electrically interconnected, in order to minimize precisely this possibility of cascading outage.

5. See e.g., R. Billington, "Power System Reliability Evaluation", Gordon \& Breach, New York, 1974.

6. P. Meier "Probabilistic Analysis of Power Plant Water Supply Systems" In preparation.

7. Reserve shutdown is that period of time that the unit is removed from service for economic reasons (which might occur during a period of low load, that can be met by another unit of lower operating cost).

8. For a detailed discussion of the relationships between availability, capacity factor, and various definitions of forced outage rate, see Meier et al, note 2, supra. 
THIS PAGE

\section{WAS INTENTIONALLY LEFT BLANK}


CHAPTER V

THE MULTI-TIME PERIOD MODEL

\subsection{Minimization of Present Worth}

The assumptions made in the previous analysis ignore the excess capacity problem, and a rigorous analysis takes into account the time point at which the conduits would be built. Obviously, if 20 conduits were used, they would not all be built concurrently, but would rather be built in a sequential manner as required by the schedule for new reactors (i.e. one per year). This makes the economic analysis more complex, and the proper criterion for the evaluation of alternatives is the discounted present worth rather than annual cost.

Using the simplest case of a once-through cooled NEC, with no adjustments for outages, consider first tunnel construction costs. The present worth of a conduit of length. $L_{T}$ built $j$ ycars hence is

$\operatorname{PWF}(i, j)$ ENR $L_{T} \quad k_{1} \cdot \phi^{2.15}$

where PWF $(i, j)$ is the present worth factor for interest rate, over $j$ years, and hence the present worth of M conduits, which would clearly be at intervals of $\frac{20}{M}$ years, but with the first built in the first year, is $^{1}$

$$
\begin{aligned}
& =\operatorname{ENR} L_{T} \cdot k_{1} \phi^{2.15}+\sum_{j=2}^{M} \operatorname{PWF}(i,(j-1)) \operatorname{ENR} L_{T} k_{1} \phi^{0.732} \\
& =\operatorname{ENR} L_{T} k_{1} \phi^{2.15}\left\{1+\sum_{j=2} \operatorname{PWF}(i,(j-1))\right\} \\
& =\text { ENR L L } \mathrm{L}_{T} \phi^{2.15} \lambda_{1}(M)
\end{aligned}
$$

Construction costs for intake-discharge structures and pumping stations would be incurred in similar years, and thus the total present worth of 
all construction costs compute to

$$
\begin{aligned}
\lambda_{1}(M) & {\left[\operatorname{ENR}\left\{L_{T} k_{1} \phi^{2.15}+k_{2}\left(\frac{Q}{M}\right)^{0.3}+k_{4}\left(\frac{Q}{M}\right)^{2.25} 0.75 L_{T} \cdot 4\left(\frac{\gamma n^{2}}{n}\right)^{0.75}\right\}\right.} \\
+\frac{G}{M} & \left.0.707 \Omega_{4} \phi a_{1} e^{-b_{1} \ell_{D} \tan \rho}\right]
\end{aligned}
$$

Next, consider pumping energy costs. As can be seen from Eq. (6), the pumping energy costs for friction losses are a function of the flow and diameter, and for each conduit the flow will increase until its design capacity is reached, at which point the next conduit will be needed. This is shown on Figure 6 for the 5-conduit case. In any year $j$, there will be $L_{j}$ conduits flowing full, and 1 conduit flowing at fraction $f_{j}$ of its capacity. Then, since pumping energy costs have the general form

$$
C=K \cdot Q^{3}
$$

where $k$ is some constant, we note that in the $j$-th year, for an NEC of ultimately $M$ conduits, the pumping energy cost is

$$
L_{j} k\left(\frac{Q}{M}\right)^{3}+k\left(f_{j} \frac{Q}{M}\right)^{3}
$$

where $L_{j}$ is the number of conuits flowing full in the $j$-th year, as given by the integer division

$$
L_{j}=\left.\frac{j}{\left(\frac{20}{M}\right)}\right|_{I}
$$

and $f_{j}$ is the fraction of pipe capacity used in the $\left(L_{j}+1\right)$ th conduit, as given by the expression

$$
f_{j}=\frac{j-1 . j\left(\frac{20}{M}\right)}{\left(\frac{20}{M}\right)}
$$


For example, in year 14 and for $M=5$,

and

$$
\cdot L_{14}=\left.\frac{14}{\left(\frac{20 .}{5}\right)}\right|_{I}=3
$$

$$
\mathrm{f}_{14}=\frac{14-3 \frac{20}{5}}{4}=0.5
$$

These results may be verified by reference to Figure 8 .

It follows that the present worth of pumping energy costs is

$$
\begin{aligned}
& \sum_{j=1}^{x} \operatorname{PWF}(i, j)\left\{L_{j} k\left(\frac{Q}{M}\right)^{3}+k\left(\frac{Q}{M} f_{j}\right)^{3}\right\} \\
& =k\left(\frac{Q}{M}\right)^{3}\left\{\sum_{j=1}^{x} \text { PWF }(i, j) \quad\left(L_{j}+f_{j}^{3}\right)\right\} \\
& =k\left(\frac{Q}{M}\right)^{3} \lambda_{2} \\
& =k^{\prime} \phi^{-5.333\left(\frac{Q}{M}\right) \lambda_{2}}
\end{aligned}
$$

where $\quad k^{\prime}=55.23 \alpha \frac{\gamma^{2}}{\eta} 2 \ell^{\prime}$

$$
\begin{aligned}
\lambda_{2} & =\sum_{j=1}^{x} \operatorname{PWF}(i, j)\left(L_{j}+f_{j}{ }^{3}\right) \\
x & =\text { index of summation, discussed below. }
\end{aligned}
$$

Finally, the total present worth is given by the sum of Eq. (41) and Eq. (44), namely

$$
\begin{aligned}
& \mathrm{PW}=\lambda_{1}(\mathrm{M}) \operatorname{ENR}\left\{\mathrm{L}_{\mathrm{T}} \mathrm{k}_{1} \phi^{2.15}+\mathrm{k}_{2}\left(\frac{\rho}{\mathrm{M}}\right)^{0.3}+\mathrm{k}_{4}\left(\frac{\rho}{\mathrm{M}}\right)^{2.25} \mathrm{~L}_{\mathrm{T}} 0.75 \phi^{-4}\right\} \\
& +\lambda_{2} \mathrm{k}^{\prime}\left(\frac{\mathrm{Q}}{\mathrm{M}}\right)^{3} \phi^{-5.333}+\lambda_{1}(\mathrm{M}) \frac{\mathrm{GT}}{\mathrm{M}} 0.707 \Omega_{4} \phi \mathrm{a}_{1} \mathrm{e}^{-\mathrm{b}_{1} \mathrm{l}_{\mathrm{D}} \tan \rho}
\end{aligned}
$$




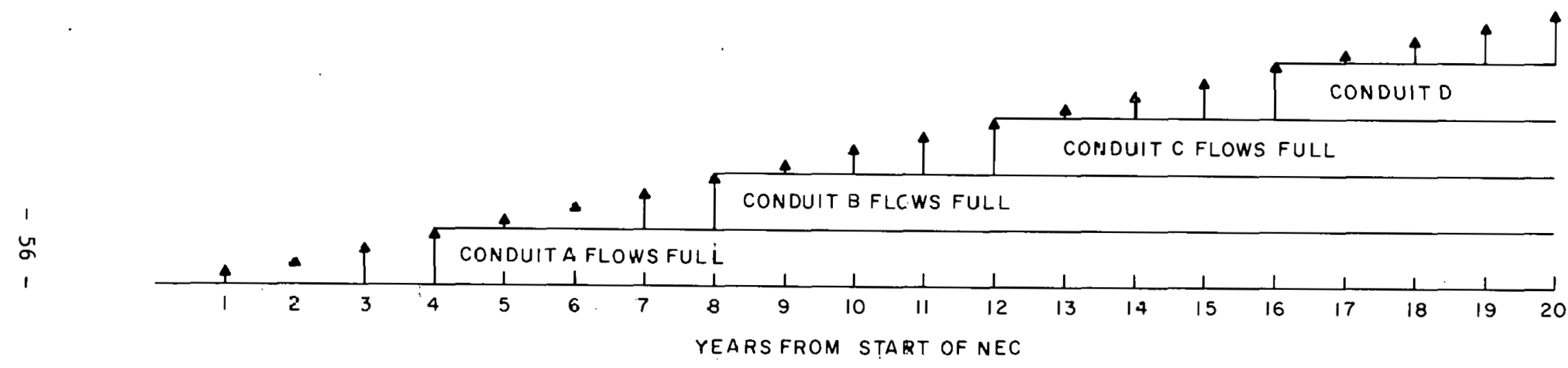

Figure 8. Pumping costs fer friction losses. 
This is, as usual, a function of the diameter, and thus the criterion for determination of the optimum diameter and number of conduits is the drivative

$$
\begin{aligned}
\frac{\mathrm{dPW}}{\mathrm{d} \phi} & =\lambda_{1}(\mathrm{M}) \quad \text { ENR } \mathrm{L}_{\mathrm{T}}^{2.15} \mathrm{k}_{1} \phi^{1.15} \\
& -\lambda_{1}(\mathrm{M}) \quad \text { ENR } \mathrm{k}_{4}\left(\frac{\mathrm{Q}}{\mathrm{M}}\right)^{2.25} \mathrm{~L}_{\mathrm{T}}^{0.75} 4 \phi^{-5} \\
& -5.333 \lambda_{2} \mathrm{k}^{\prime}\left(\frac{Q}{\mathrm{M}}\right)^{3} \phi^{-6.333} \\
& +\lambda_{1}(\mathrm{M}) \frac{\mathrm{G}_{\mathrm{T}}}{\mathrm{M}} 0.707 \Omega_{4} \mathrm{a}_{1} \mathrm{e}^{-\mathrm{b}_{1} \ell_{\mathrm{D}} \tan \rho}
\end{aligned}
$$

which, when set equal to zero, can be solved for the optimum diameter $\phi^{*}(\mathrm{M})$, as in Chapter III for the annual cost case.

Analogous expressions for the evaporative cooled case, and for designs incorporating the effect of scheduled malntenalle did forced outage, are readily derived. The computer program used to generate numerical results, documented in a separate report, ${ }^{2}$ incorporates all the options discussed thus far.

\subsection{Results:}

Tables 12, 13, and 14 show the results of this present worth optimization for each of the three NEC surrogate sites in Ocean County. We note that the optimal number of conduits in all three cases is two $(M=2)$, although in the evaporatively cooled sites the difference between one and two conduits, in present worth terms, is quite small (e.g. for the Inland site, Table 13, the total present worth for $M=1$ and $M=2$ is $\$ 114.5 \mathrm{~m}$ and $\$ 10.9 .65 \mathrm{~m}$, respectively.)

A comparison of the optimal diameter of the time-phased NEC, computed on the basis of minimizing total present worth, with that of the constant NEC, computed on the basis of minimizing annual cost, illustrates some interesting features. For $M=1$, the present worth optimum for the Ft. Dix intake is $13.77 \mathrm{ft}$. (Table 12), whereas the annual cost optimum under corresponding conditions is $12.64 \mathrm{ft}$. (Table 5). The smaller diameter 
TABLE 12 SYSTEM COSTS USING BOREU TUNNELS, FT, OIX

EVAPUHATIVE COULING SYSTEM

INETA

SCHEOULE MAIRENANCE DAYS TYA

QUSBAH ENEHGT COST

EVE

TO OCEAR, MILES

STATIC REAU,FY.

CONCENTFATIOA FACTOG

MAXIMUM UIAMETER,FT.

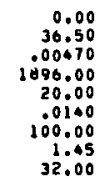

- CaCEU outage pate

E cocion

SYSTEM ENEROY COST.STKMM

INTEAEST FATE

DELTA

PUMP EFF ICIENCY

MInIMUP OIAME TER, T.

CONSURPTIVE USE AT FULL OUTPU

average avaILAGILIIY

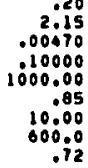

$m=$

\begin{tabular}{|c|c|c|c|c|c|c|c|c|c|}
\hline & $\begin{array}{c}\text { O-PEAN } \\
\text { CFS }\end{array}$ & $\begin{array}{c}\text { U-AVER, } \\
\text { CFS }\end{array}$ & $\begin{array}{l}\text { OPTIMAL } \\
\text { UIAM,FT }\end{array}$ & $\begin{array}{c}\text { CON ON } \\
\text { CONDUIT }\end{array}$ & $\begin{array}{l}\text { I R U C I } \\
\text { INTAKE: } \\
\text { UISCHAHGE }\end{array}$ & $\begin{array}{l}10 \text { n } \\
\text { punps }\end{array}$ & $\begin{array}{l}\text { PUMP ING } \\
\text { ENEKGY } \\
\text { COST }\end{array}$ & $\begin{array}{l}\text { PAICIION } \\
\text { MEADIPER } \\
\text { CONOUIT }\end{array}$ & $\begin{array}{l}\text { TOTAL } \\
\text { PRESENT } \\
\text { WORIM }\end{array}$ \\
\hline $\begin{array}{l}\text { INIAARE } \\
\text { OISCHAFIGE }\end{array}$ & $\begin{array}{l}1740.0 \\
1200.0\end{array}$ & $\begin{array}{r}1392.0 \\
960.0\end{array}$ & $\begin{array}{l}10.04 \\
10.00\end{array}$ & $\begin{array}{l}75.8+1 \\
64.423\end{array}$ & $\begin{array}{l}4.177 \\
0.000\end{array}$ & $\begin{array}{l}43.421 \\
21.300\end{array}$ & $\begin{array}{l}.587 \\
.197\end{array}$ & $\begin{array}{l}890.650 \\
655.933\end{array}$ & $\begin{array}{r}124.020 \\
85.020\end{array}$ \\
\hline
\end{tabular}

CAPIIAL CUSI PER KO

$M=2$

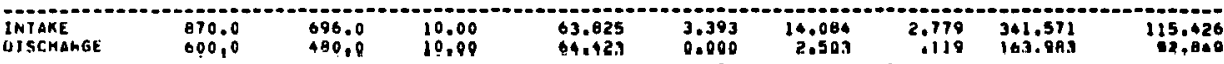

CAPITAL CUSP PLM KO 12 i 35

$M=5$

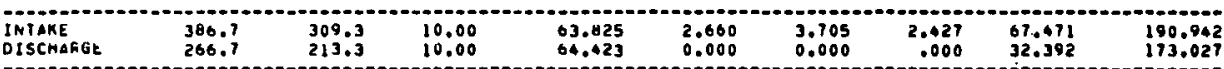

CAPITAL COST PER KII 28.00

$m=10$

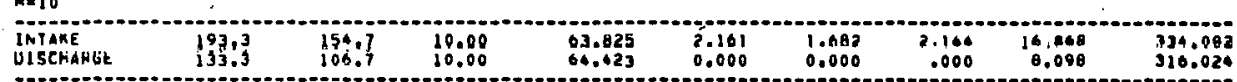

$M=20$

INTAKE

CAPIIAL CUST PEH KI 109.10 
TAGLE 13 STSTEM COSTS USING BORLU TUMMELS, IMLAMU

\begin{tabular}{|c|c|c|c|c|c|}
\hline 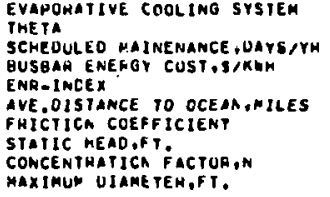 & $\begin{array}{r}0.00 \\
36.50 \\
.00470 \\
1896.00 \\
10.00 \\
.0140 \\
80.00 \\
1.45 \\
32.00\end{array}$ & & 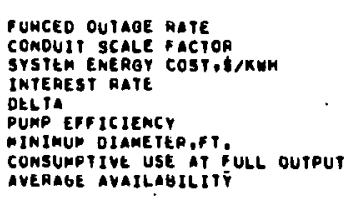 & $\begin{array}{r}.20 \\
2015 \\
.00070 \\
.10000 \\
1000.00 \\
10.05 \\
000.0 \\
.72\end{array}$ & $"$ \\
\hline
\end{tabular}

$M=1$

\begin{tabular}{|c|c|c|c|c|c|c|c|c|c|}
\hline & $\begin{array}{l}\text { Q-PEAK } \\
\text { CFS }\end{array}$ & $\begin{array}{l}\text { U-AVER, } \\
\text { CFS }\end{array}$ & $\begin{array}{l}\text { OPTIMAL } \\
\text { OIAM,FY }\end{array}$ & $\begin{array}{c}\text { Con s } \\
\text { CONDUIT }\end{array}$ & $\begin{array}{l}\text { A UCI } \\
\text { INTAKE. } \\
\text { UISCMAGGE }\end{array}$ & Pumps & $\begin{array}{l}\text { PUMP ING } \\
\text { ENEREY } \\
\text { COST }\end{array}$ & $\begin{array}{l}\text { FRICIION } \\
\text { HEAO,PER } \\
\text { CONDUIT }\end{array}$ & $\begin{array}{l}\text { TOTAL } \\
\text { PAESENT } \\
\text { WORTM }\end{array}$ \\
\hline $\begin{array}{l}\text { INTAKE } \\
\text { UISCMAAGE }\end{array}$ & $\begin{array}{l}1740.0 \\
1200.0\end{array}$ & $\begin{array}{r}1392.0 \\
960.0\end{array}$ & $\begin{array}{l}11.14 \\
10.00\end{array}$ & $\begin{array}{r}10.590 \\
32.010\end{array}$ & $\begin{array}{l}0.177 \\
0.000\end{array}$ & $\begin{array}{l}24.767 \\
11.842\end{array}$ & .207 & $\begin{array}{l}388.606 \\
334.063\end{array}$ & $\begin{array}{r}69.820 \\
44.736\end{array}$ \\
\hline
\end{tabular}

CAPIIAL CUST PEH KU

$m=2$

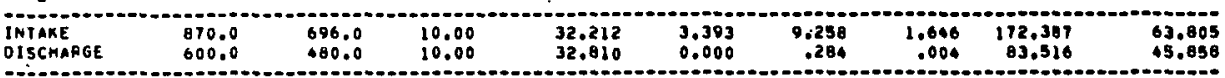

capiral cost peatad

$M=5$

\begin{tabular}{|c|c|c|c|c|c|c|c|c|c|}
\hline $\begin{array}{l}\text { INTAKE } \\
\text { DISCHAAGE }\end{array}$ & $\begin{array}{l}380.7 \\
266.7\end{array}$ & $\begin{array}{l}309.3 \\
213.3\end{array}$ & $\begin{array}{l}10.00 \\
10.00\end{array}$ & $\begin{array}{l}32.212 \\
32.010\end{array}$ & $\begin{array}{l}2.660 \\
0.000\end{array}$ & $\begin{array}{l}2.778 \\
0.000\end{array}$ & $\begin{array}{r}1.609 \\
.000\end{array}$ & $\begin{array}{l}34.052 \\
16.087\end{array}$ & $\begin{array}{r}102.618 \\
08.121\end{array}$ \\
\hline
\end{tabular}

CAPITAL CUST PE. KW IA, GA

$M=10$

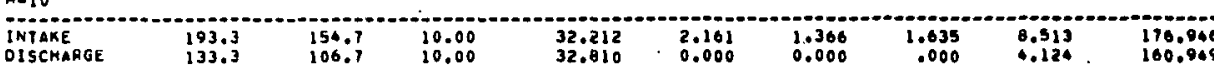

CAPITAL CUSI PER KM 28.56

$M=20$

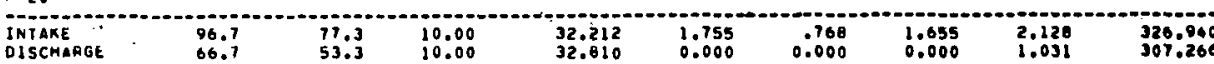

CAPITAL CUST PEH KE 56.29 
TABLE 14 SYSTEM COSIS USING GOHEO TUMMELS, GAY

ONCE-THHUUGO COOLING

THE TA

SCMEOULEU MAINENAWCE, UAYS YYA

BUSHAH ENERGY COST, STKUM

ENA-1NOEX

AVE, DISTANCE TO OCEAR, WILES

GICTICA CUEFFICIEN

STATIC MEAD,FTE.

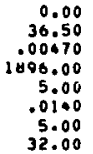

FORCEU OUIAGE RATE

CONDUII SCALE FACTON

SYSTEM ENEROY

IATEKEST AATE

OELTA

PUMP EFFICIENCY

M IAIMUN OIAMETER,Fi:

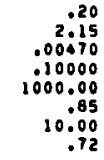

$m=1$

\begin{tabular}{|c|c|c|c|c|c|c|c|c|c|}
\hline & $\begin{array}{l}\text { U-PEAK } \\
\text { CFS }\end{array}$ & $\begin{array}{l}\text { UAVER. } \\
\text { CFS }\end{array}$ & $\begin{array}{l}\text { OPIIMAL } \\
\text { OIAM,FT }\end{array}$ & $\begin{array}{c}\text { CONS } \\
\text { CONDUIT }\end{array}$ & $\begin{array}{l}\text { I RUCE } \\
\text { INIAKE: } \\
\text { UISCHARGE }\end{array}$ & $\begin{array}{l}\text { I ON } \\
\text { PUMPS }\end{array}$ & $\begin{array}{l}\text { PUMPING } \\
\text { ENERUY } \\
\text { COST }\end{array}$ & $\begin{array}{l}\text { FRICIION } \\
\text { READ,PER } \\
\text { CONDUIT }\end{array}$ & $\begin{array}{l}\text { TOTAL } \\
\text { PRESENT } \\
\text { WORTH }\end{array}$ \\
\hline & 35010.0 & 28000.0 & 32.00 & 385.422 & 28.145 & 266.797 & 6.294 & 554.098 & 686.659 \\
\hline & $\begin{array}{r}- \text { SLK } \\
\text { LEA }\end{array}$ & $\begin{array}{l}\text { TEMP . } \\
\text { T. }\end{array}$ & 351.50 & & $\begin{array}{l}\text { DISTANCE } \\
\text { HATEN D }\end{array}$ & $\begin{array}{l}\text { E CFFSHOK } \\
\text { EPIH.FT. }\end{array}$ & & & $\because 1$ \\
\hline
\end{tabular}

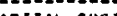

LEAGTH,FT

DATEA DEPTH,FT.

me 2

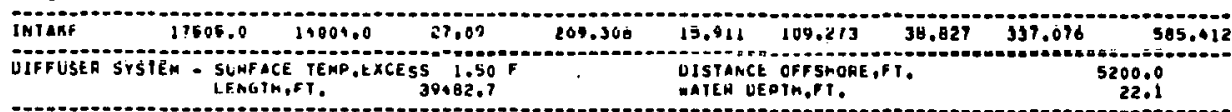
39482,7 ATEN VEDTH,PT.

$M=5$

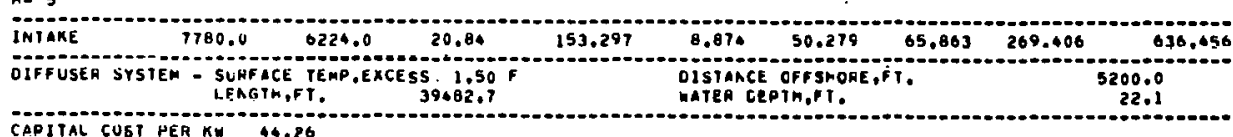

CAPITAL CUST PER KY

$M=10$

INTAKE
UIFFUSER SYSTEM - SUFACE TEMP.EXCESS $1.50 \mathrm{~F}$
LEAGTH,FT.

$k=20$

INTAKE

LENGIN,FT.

39482.1

matén depIM,FI.

22.1

CAPITAL GUST PER KI GIIA 
of the present worth case is as it should be, because for the first 19 years such a pipe flows only partially full, and the implied excess capacity would tend to force down optimal tunnel diameter and cost. 3 A similar effect can be observed for the once-through case (compare the $M=2$ results of Tables 7 and 14). Depending on the assumptions made for reactor retirement (would a 30 year old reactor be replaced by another after thirty years, thus maintaining the energy center at planned capacity, or would the NEC begin to be gradually phased down, falling from 20 reactors in year 30 to zero after 50 years?), the use of the present worth criterion may thus be open to some question. If, in fact, one posits the continuous park, and noting that a tunnel may have a life well in excess of 50 or even 10.0 years, then the present worth criterion will yield optimal diameters that become closer to the annual cost optima as the length of time horizon incrcases. This there is some ambiguity in the index of summation, as in Eq. (45) - and we chose $x=20$ as a matter of expediency rather than rigor. 
THIS PAGE

\section{WAS INTENTIONALLY LEFT'BLANK}




\section{APPENDIX: Derivation of the Present Worth Pumping}

Energy Costs in the Stochastic, Evaporatively

\section{Cooled Case}

In the evaporatively cooled case, pumping energy costs have the form

$$
C=k^{\prime} Q^{3}+k^{\prime \prime} Q
$$

where $k^{\prime}$ and $k^{\prime \prime}$ are defined in Eq. (39) and (40) respectively. It follows that the pumping energy cost in the $j-t h$ year, in an NEC of ultimately $M$ conduits, is :

$$
P=L_{j}\left\{k^{\prime}\left(\frac{Q}{M}\right)^{3}+k^{\prime \prime} \frac{Q}{M}\right\}+k^{\prime}\left(f_{j} \frac{Q}{M}\right)^{3}+k^{\prime \prime} f_{j} \frac{Q}{M}
$$

where $L_{j}$ and $F_{j}$ are as defined by Eq. (42) and (43) respectively. But if $Q$ is a random variable, $P$ is also a r.v.; thus, taking expectations

$$
\begin{aligned}
E\{P\} & =L_{j}\left[k^{\prime} E\left\{\left(\frac{Q}{M}\right)^{3}\right\}+k^{\prime \prime} E\left\{\frac{Q}{M}\right\}\right]+k^{\prime} f_{j}^{3} E\left\{\left(\frac{Q}{M}\right)^{3}\right\}+k^{\prime \prime} f_{j} E\left\{\frac{Q}{M}\right\} \\
& =E\left\{\left(\frac{Q}{M}\right)^{3}\right\}\left(k^{\prime}\left(L_{j}+f_{j}{ }^{3}\right)\right)+E\left\{\left(\frac{Q}{M}\right)\right\} k^{\prime \prime}\left(L_{j}+F_{j}\right)
\end{aligned}
$$

Hence, the expected value of present worth of $\mathbf{x}$ years of pumping is

$$
E\{P W\}=\sum_{j=1}^{x} \operatorname{PWF}(i, j) \quad E\{P\}
$$

But from Eq. (45)

$$
\sum_{j=1}^{x} \operatorname{PWF}(i, j)\left(L_{j}+f_{j}^{3}\right)=\lambda_{2}
$$

hence, if similarly we define

$$
\sum_{j=1}^{x} \operatorname{PWF}(i, j) \cdot\left(L_{j}+f_{j}\right)=\lambda_{3}
$$

Then 
But

$$
\left.E\{P W\}=E\left\{\frac{(Q Q}{M}\right)^{3}\right\} k^{\prime} \lambda_{2}+E\left\{\left(\frac{Q}{M}\right)\right\} k^{\prime \prime} \lambda_{3}
$$

$$
E\left\{\left(\frac{Q}{M}\right)^{y}\right\}=\sum_{r=1}^{\bar{K}} P_{r}\left(\frac{Q_{r}}{M}\right)^{y}
$$

Where

$$
\begin{aligned}
& P_{r}=\left(\begin{array}{l}
\bar{K} \\
r
\end{array}\right) \omega^{r}(1-\omega)^{\bar{K}-r} \\
& Q_{r}=\frac{\bar{K}-j}{\bar{K}} Q \psi_{s}(M)
\end{aligned}
$$

Thus, finally

$$
\begin{aligned}
\mathrm{E}\{\mathrm{PW}\} & =\sum_{\mathrm{r}=1}^{\overline{\mathrm{K}}} \mathrm{P}_{\mathrm{r}}\left(\frac{\mathrm{Q}_{\mathrm{r}}}{\mathrm{M}}\right)^{3} \mathrm{k}^{\prime} \lambda_{2}+\sum_{r=1}^{\overline{\mathrm{K}}} \operatorname{Pr}\left(\frac{\mathrm{Q}}{\mathrm{M}}\right) \mathrm{k}^{\prime \prime} \lambda_{3} \\
& =\sum_{\mathrm{r}=1}^{\overline{\mathrm{K}}} \mathrm{P}_{\mathrm{r}}\left\{\mathrm{k}^{\prime} \lambda_{2}\left(\frac{\mathrm{Q}_{\mathrm{r}}}{\mathrm{M}}\right)^{3}+\mathrm{k}^{\prime \prime} \lambda_{3} \frac{\mathrm{Q}_{\mathrm{r}}}{\mathrm{M}}\right\}
\end{aligned}
$$

where

$$
\begin{aligned}
& \mathrm{k}^{\prime}=55.23 \propto \frac{\gamma \mathrm{n}^{2}}{n} \& \phi^{-5.3333} \\
& \mathrm{k}^{\prime \prime}=11.81 \frac{\gamma \mathrm{n}}{\mathrm{n}} \mathrm{h}_{\mathrm{s}}
\end{aligned}
$$

\section{NOTES TO CHAPTER V}

1. The rase of $M=1$ 1s obviously a special case, for which the term incorporating the present worth exprescion is uщltced.

2. P. Meier "NECWSO-A Computer Code for Water Conveyance System Optimization: User Manual and Documentation" Forthcoming Report; Broolchavell Narional Laboratory, Regional Tineigy Etudies Program.

3. For the remaining cases of $M>1$ in the evaporatively cooled alternatives, the minimum diameter constraint obscures this effect, since the $10 \mathrm{ft}$. lower limit is imposed. 


\section{Relationship to Cooling System Configuration}

\subsection{Once-Through Cooling}

Thus far in our analysis of the once-through cooled NEC at the Bay site we have assumed that the cooling water flow would be equivalent, on a cfs per installed Mw basis, to that of the Oyster Creek facility. Although the assumed value of $38,9.00$ cfs for the completed NEC matches quite well with the 40,000 cfs that would represent average conditions, 1 there are in fact substantial variations in flows. ${ }^{2}$ Consequently, one may pose the question as to the sensitivity of our computer model simulation results to the assumed flow value.

Table 15

Sensitivity of Once-Through System Cost to Flow

\begin{tabular}{|c|c|c|c|c|}
\hline $\begin{array}{l}\text { Flow per } \\
\text { reactor, cfs }\end{array}$ & $\begin{array}{l}\text { Optimal } \\
\text { diameter,ft. }\end{array}$ & $\begin{array}{c}\text { Optimal } \\
M^{*} \\
\end{array}$ & $\begin{array}{l}\text { Unit Tunnel } \\
\text { construction } \\
\text { cost, million } \$\end{array}$ & $\begin{array}{l}\text { Total present } \\
\text { worth, million } \$\end{array}$ \\
\hline 1,000 & 21.1 & 2 & 157 & 347 \\
\hline 1,500 & 24.6 & 2 & 218 & 475 \\
\hline 1,945 & 27.0 & 2 & 269 & 585 \\
\hline 2,500 & 29.8 & 2 & 330 & 713 \\
\hline
\end{tabular}

The results of runs using a variety of flow values are summarized on Table 15. As once would expert, optimal tunnel diameter, tunnel construction cost, and total present worth all rise whth increases in flow. However, the optimal number of conduits remains unchanged for the range of flow values examined. 


\subsection{Concentration Factor}

The calculations for the evaporatively cooled NEC alternatives have assumed a concentration factor of 1.45. This figure is consistent with. our preliminary assessment, ${ }^{3}$ and is based on the current consenses as to acceptable levels of salt build-up in cooling towers. One should note, however, that no significant experience with saltwater cooling towers is yet available, and that the quantitative relationship between salt concentration, corrosiveness, and tower costs is still largely a matter of conjecture, however well recognized such effects are qualitatively. Thus, even if a concentration ratio of 1.45 does represent the current consensus as to an allowah1e value, it would seem prudent to examine the impact of variations in this frator on watcr system cuuflyuracion and torial system cost.

The impact of variations in $\mathrm{N}$ on the water conveyance system for the Inland NEC is displayed on Table 16. We note that system costs are indeed very sensitive to this parameter.

Table 16

\begin{tabular}{|c|c|c|c|c|c|}
\hline \multirow{2}{*}{\multicolumn{2}{|c|}{ Concentration }} & \multicolumn{3}{|c|}{ Sensitivity to $\mathrm{N}$, Inland NEC } & \multirow[b]{2}{*}{$\begin{array}{l}\text { Construction } \\
\text { cost per } \\
\text { tunnel } \\
\times 10^{6} \\
\end{array}$} \\
\hline & $\begin{array}{l}\text { Optimal } \\
M^{*}-\end{array}$ & $\begin{array}{c}\text { Average flow } \\
\text { per intake } \\
\text { Conduit } \\
\text { cfs } \\
\end{array}$ & $\begin{array}{c}\text { Optimal } \\
\text { intake } \\
\text { Diameter } \\
f t \\
\end{array}$ & $\begin{array}{l}\text { Total } \\
\text { present worth } \\
\text { of intake } \\
\text { II } 10^{\mathrm{f}} \\
\end{array}$ & \\
\hline 1.2 & $?$ & 1,296 & 11.3 & 96.3 & 40.6 \\
\hline 1.45 & 2 & 696 & 10.00 & 63.8 & $32: 2$ \\
\hline 2.0 & 1 & 432 & 10.00 & 49.7 & 32.2 \\
\hline 3.0 & 1 & 324 & 10.00 & 43.7 & $32: 2$ \\
\hline
\end{tabular}

\subsection{Wet/Dry Plume Control Towers}

One af the oprlons consilered in our preliminary analysis of cooling systems was the hybrid wet/dry cooling tower, which we felt might be necessary to limit salt drift and plumes. However, the operation of wet/dry 
towers may be quite complex, with the dry section, for example, designed to handle. the entire cooling load at ambient.temperatures below some preselected value, and a comprehensive analysis of such towers falls beyond the scope of this report. Nevertheless, the orders of magnitudes of cost involved, and the relationship of wet/dry ratios to water conveyance system design, can readily be obtained by making a few assumptions such that our existing computer program can be used.

It should be clear that if some fraction of the wet cooling, say. $\lambda$, is replaced by dry cooling, then the total consumptive water use of the NEC would also be reduced by that same fraction. Since it is the net consumptive use that, together with the concentration factor $N$, sets the water flow requirement, we may simply rerun the computer model as a function of the total evaporative flow corresponding to various fractions of dry cooling. The results, for the Fort Dix NEC site, ${ }^{4}$ are displayed on Table 17. We note that the water conveyance system costs do indeed fall, although a reduction of total evaporative loss by 50 percent, i.e. from 600 cfs to 300 cfs, does not reduce total present worth by the same fraction.

Given that the water conveyance system costs do indeed fall as the fraction of dry cooling increases, what is the effect on total cooling system costs? And in particular, is the decrease in water conveyance costs sufficient to offset the increase in tower cost? Table 18 shows that this is not the case, and that the total system construction cost, expressed in terms of $\$ / \mathrm{Kw}$, rises significantly with increases in $\lambda$. In fact, if the operating cost penalty of dry cooling were included, ${ }^{5}$ and the comparisons made on a total lifetime present worth basis, increases in $\lambda$ would result in even more dramatic increases in total cost.

\subsection{Feasibility of Once-Through Cooling}

The preliminary assessment expressed the judgement that the cost of once-through cooling at an Inland Site (say in excess of 10 miles from the water source) would be greater than that for evaporatively cooled alternatives. This judgement was based on linear extrapolation of the Seabrook and other current 2-unit nuclear projects using tunnels, thus ignoring scale economies in tunnel and pumping station construction, 
Table 17

Ft. Dix NEC Costs as a Function of the.

Dry Cooled Fraction

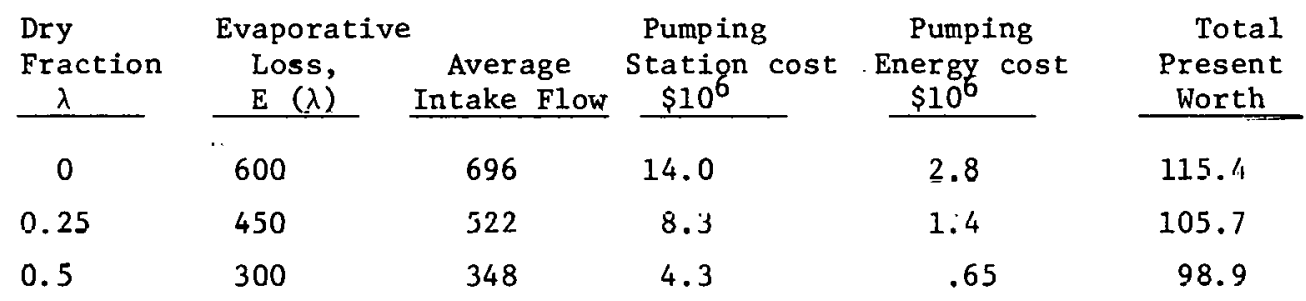

Al1 Data for $M=2$

lable 18

Total Ft. Dix Cooling System Capital Costs

as a Function of the Dry-Cooled Fraction

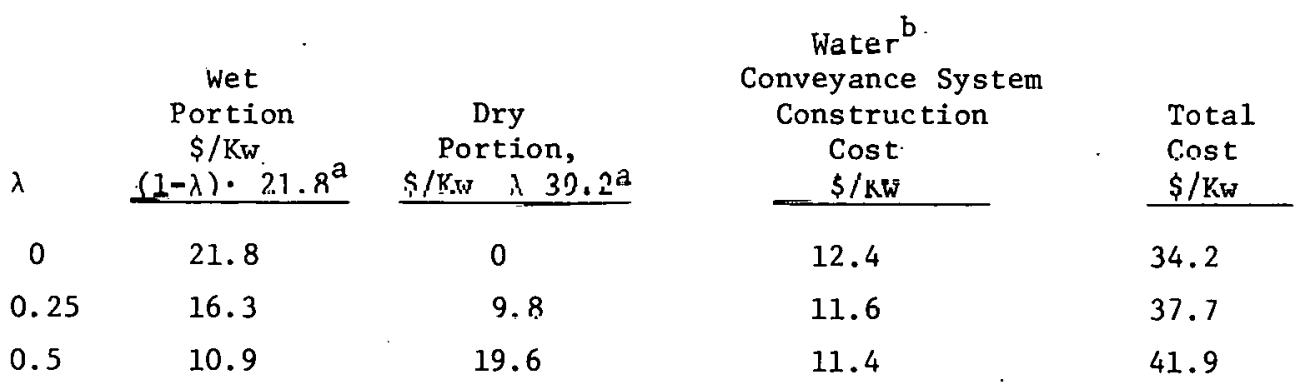

aAstil inU NRC-NELSE; Vol. III, p.3-48 (liabLe 3.4)

bata are for $M=$ ? 
as well as ignoring pumping energy savings due to smaller friction losses per gallon transported in a conduit of much larger diameter.

The more detailed analysis developed in this report leads, perhaps unexpectedly, to similar conclusions. Table 19 summarizes the results of once-through cooling cost systems at the Bay, Inland, and Ft. Dix sites, as compared to their corresponding evaporatively cooled systems. Comparing first the construction costs, expressed as $\$ / \mathrm{KW}_{\mathrm{W}}(\mathrm{e})$, we see that the once-through system is more expensive than its evaporative counterpart in all cases. The difference ranges from about 25 percent more expensive at the. Bay site, to about three times as expensive at the Ft. Dix site.

When one includes operating costs into the analysis, and makes the present worth comparison, once-through cooling becomes three to five times as expensive as evaporative. The reason for the larger difference in present worth romparisnns is the inordinately high cost of pumping energy for the once-through alternative--because of the upper bound on tunnel size, the balance between tunnel cost and pumping cost shifts to the latter. Relaxation of the upper bound on tunnels would make the once-through system alternatives relatively less expensive.

This point can also be made by comparing the difference in cost at the Bay site, for which once-through cooling is 2.6 times as expensive, to the Ft. Dix site, for which once-through cooling is 4.9 times as expensive. Clearly, pumping energy costs become relatively more important as the length. of the conduit increases.

How do these results compare with similar computations based on conventional cut-and-fill conduits? If one defines $\Omega$ as the ratio of present worth of once-through to evaporative cooling and plots this value as a function of distance to the water source for both tunnels and cut-andfill conduits, the results of Figure 9 emerge. We see that for the conventional conduit, once-through is the indicated alternative at the Bay site; as one moves inland, however, the advantage shifts to the evaporative system, although the dependancy of cost on distance is much less than in the tunnel case. 6 
Tabile 19

Comperis.jn of Evaporative and Once-Through Cooled Systems For

Bored' Tunnels

Evaporative System

\begin{tabular}{l} 
Distance to \\
Water Source, \\
Miles \\
\hline
\end{tabular}

Iota- Fresent Construction Cost, $\$ / \mathrm{Kw}$

Worth

Conveyance

Tost, $\$ / \mathrm{KW}$

System

Towers

Total

2.7
3.6

20.0

Total

$\bar{J}=\left\{\begin{array}{l}1 \\ 2\end{array}\right.$

$64+200=264$

20.0

22. 7

23.6

20.0

24.8

20.0

26.5
Once-Thr
Construction
Cost
$\$ / \mathrm{Kw}$

28.3

32.9

4.8

6.5

21.8

30.5

$21.8 \quad 34.1$

8.7
12.3

$208+2=:=425$

52

61

96

114

ystem

Total Present Worth $\$ \times 10^{6}$

686

585

1260

1098

2348

2085 


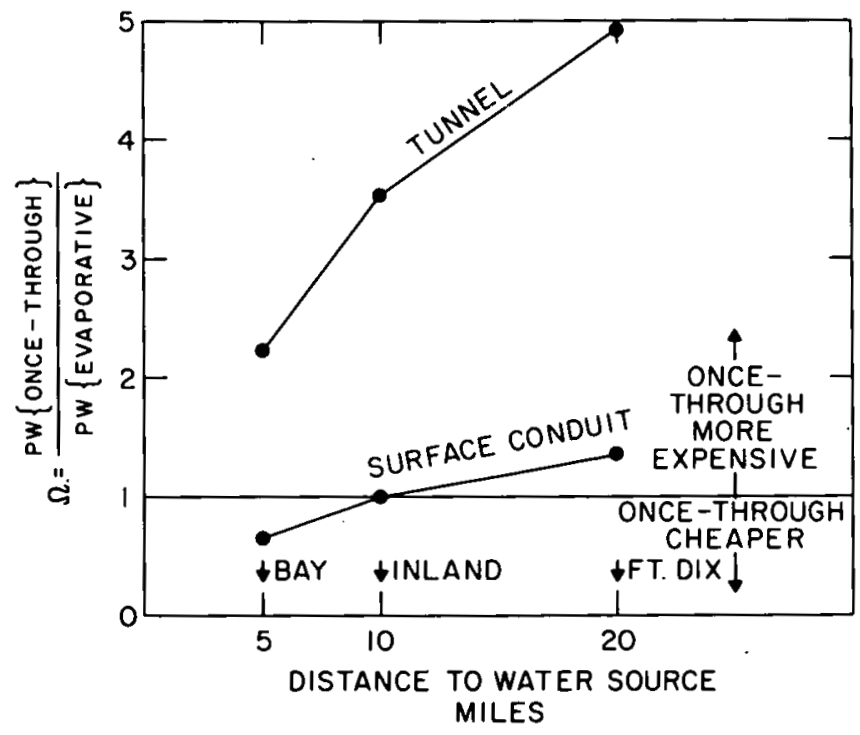

Figure 9. Comparison of surface cundulta and tunnels.

In conclusion we note that the judgements expressed in our preliminary assessment of the Ocean County NEC regarding the high cost of once-through cooling appear to be confirmed by our detailed analysis. The necessity for tunnels makes evaporative cooling the indicated choice at all three Ocean County locations examined. Scale economies cannot be fully expoited due to upper bounds on maximum tunnel diameter, which in turn forces the optimum system configuration into high pumping energy requirements, with the net result that the linear extrapolation procedure used in the preliminary analysis is not at all unreasonable. 
1. The survey of nuclear reactors in WASH 1355, "Nuclear Power Facility Performance. Characteristics for Making Environmental Impact Assessments", Dec. 1974, notes that the average flowrate for a $1200 \mathrm{Mw}$ facility is on the order of $2000 \mathrm{cfs}$.

2. An extrapolation of the Seabrook. flow, for example, would yield a total of only 17,530 cfs, less than half the Oyster Creek value.

3. See BNL 50465, p. 242.

4. We use Ft. Dix rather than Inland because Ft. Dix has the highest water system cost, and would be expected to show the greatest impact of water system cost savings.

5. Not only die power costs higher for dry cooling towers, but the plant capability at design condition is reduced; a plant rated at $1200 \mathrm{Mw}(\mathrm{e})$ under once-through conditions might be rated at only $1177 \mathrm{Mw}(\mathrm{e})$ for mechanical draft wet cooling, and as little as 1022 Mw(e) for mechanical draft dry cooling (see NRC-NECSS, Vol. III, Table 3.4).

6. The present worth amounts compute as follows; Bay site $-\$ 243 \mathrm{~m}$ for evaporative, $\$ 320 \mathrm{~m}$ for once-through; Inland site- $\$ 277 \mathrm{~m}$ for evaporative, \$269. $\mathrm{m}$ for the once-through; Ft. Dix - \$359 m for evaporative, $\$ 484 \mathrm{~m}$ for once-through. 
Since one of the key issues in the analysis of nuclear energy centers as a siting option is the comparison to conventional, dispersed siting, the main report addresses in some detail the differences between the New Jersey NEC, assumed to be in Ocean County, and a postulated scenario of dispersed nuclear reactors for the PJM Power Pool. ${ }^{1}$ In this section, therefore, we address the question of differences in water conveyance system costs for the clustered and dispersed siting modes, using the same scenario of dispersed sites for comparisons. The assumed construction dates for individual reactors in this dispersed scenario, at the sites identified in Figures 10, 11 and 12 , are as follows: ${ }^{2}$

Limerick (1997, 1998)

Susquehanna (1991, 1992)

Lower Delaware (1987, 1988, 1989, 1990)

Lower Chesapeake Bay (2000, 2002, 2004, 2006).

offshore B (19.93, 1994, 199.5, 1996).

offshore C (1999, 2001, 2003, 2005)

The major difference between the dispersed and NEC cases in regard to their water conveyance systems is the need for flow augmentation storage reservoirs for the Limerick, Susquehanna, and Delaware Bay Sites, and the absence of long water conveyance conduits at all of the dispersed sites.

Table 20 summarizes the cost of Reservoir and Intake-Discharge structures for the dispersed case. $j$ indicates the year of construction from the start of NEC operation. $j=0$ denotes that the corresponding facility would be complete at the beginning of the first year. Because the dispersed sites are all so close to their water sources, implying minimal static head differences, and, due to the very short length of the necessary conduits, minimal friction losses, pumping and conduit costs would be quite nominal and can be ignored. Indeed, they would be of the same order of magnitude as the local, within-park conduit costs of the NËC case, which we have also 1gnored. 


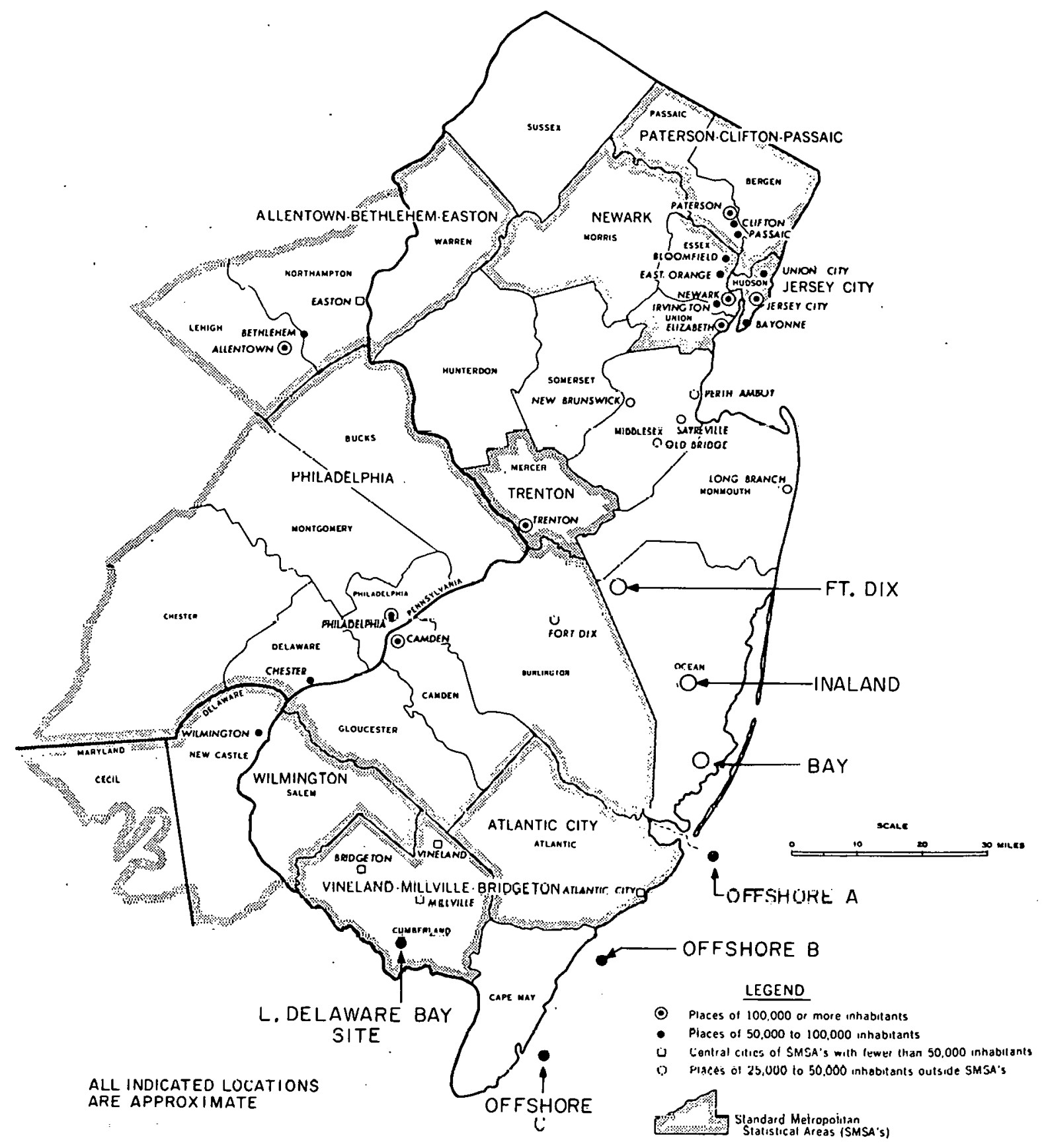

Flgure 10. Locarion of New Jersey sites. 


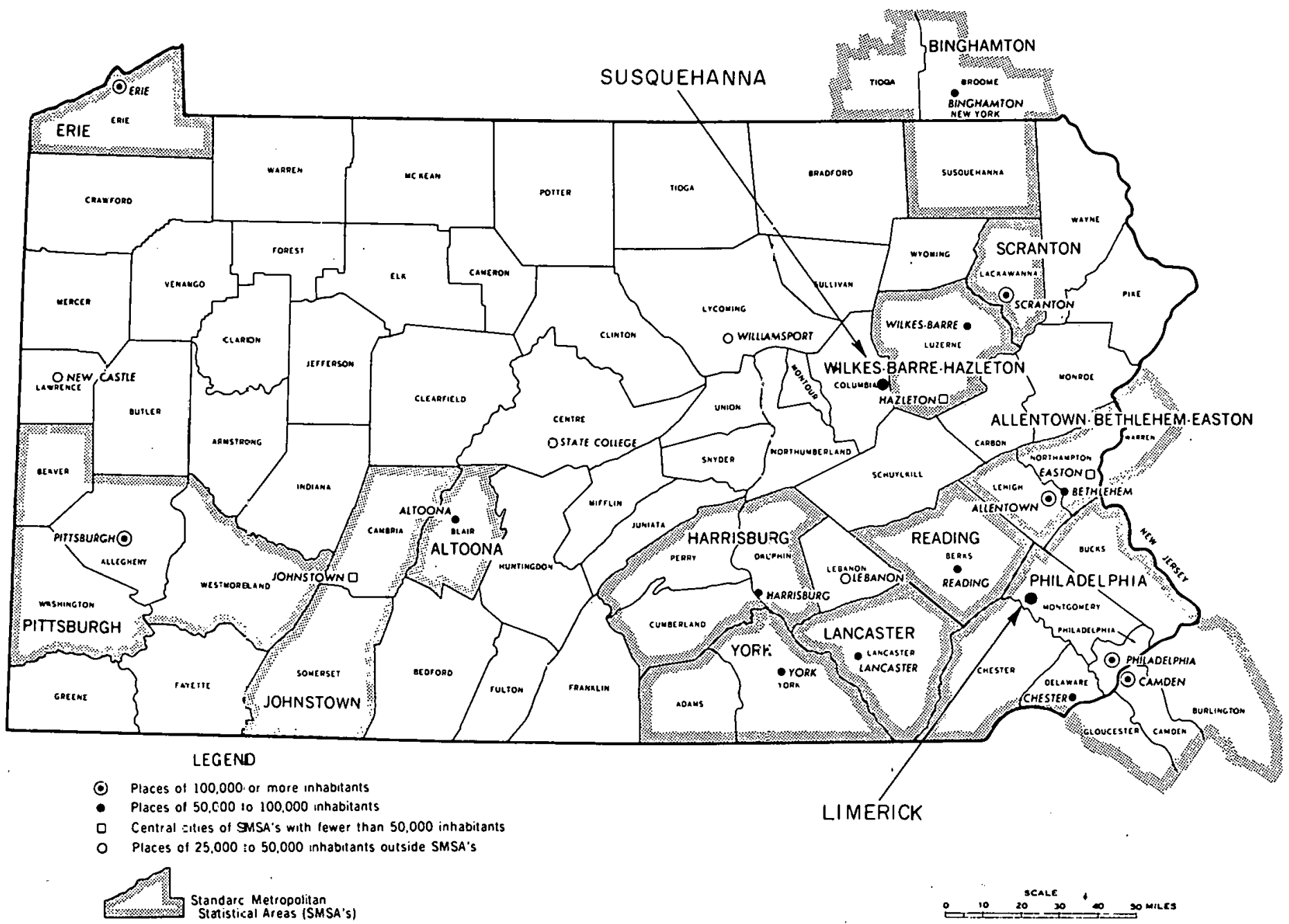

Figure 11. Location of expansion sites. 


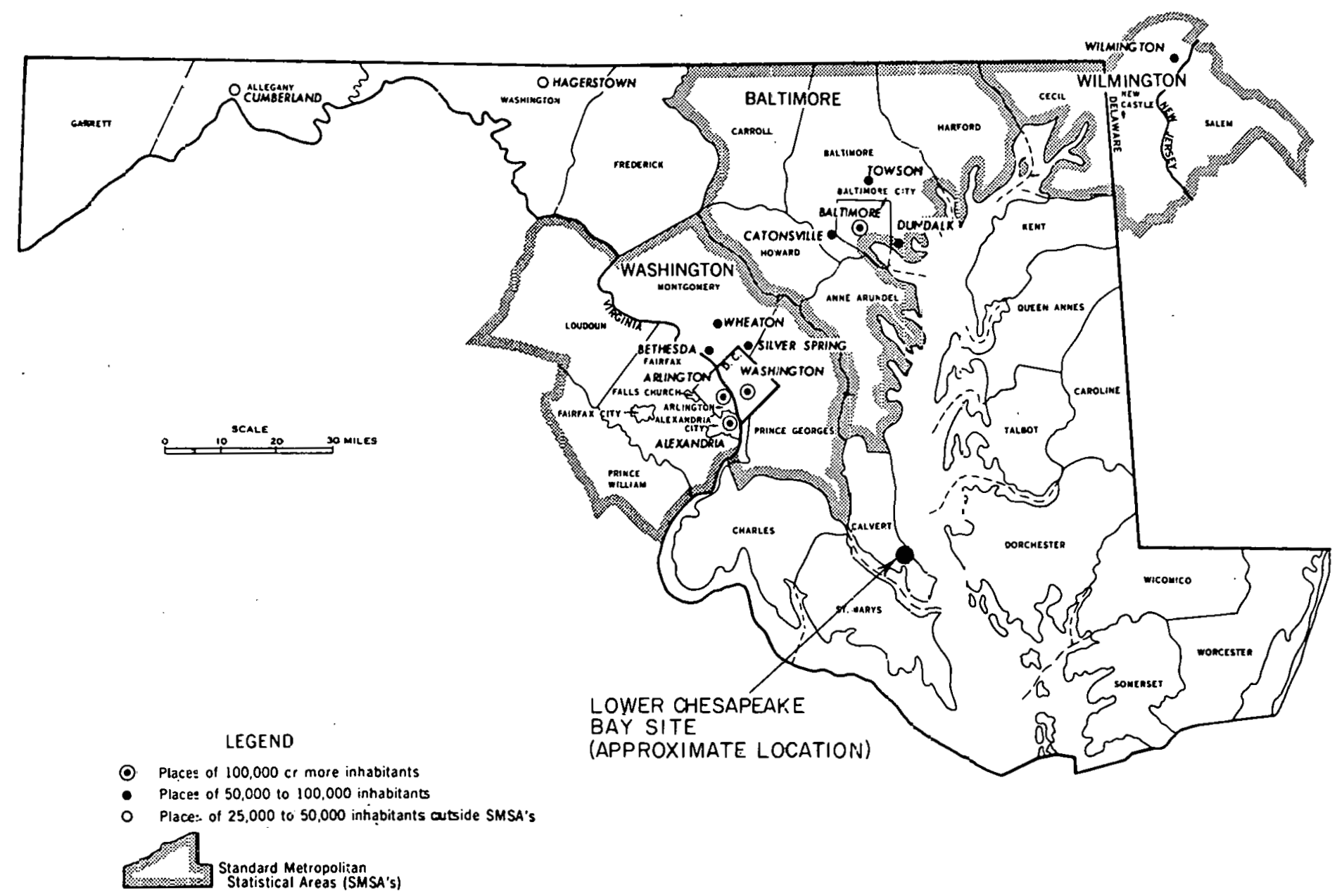

Figure 12. Location of lower Chesapeake Bay site. 
Table 20

THE DISPERSED CASE

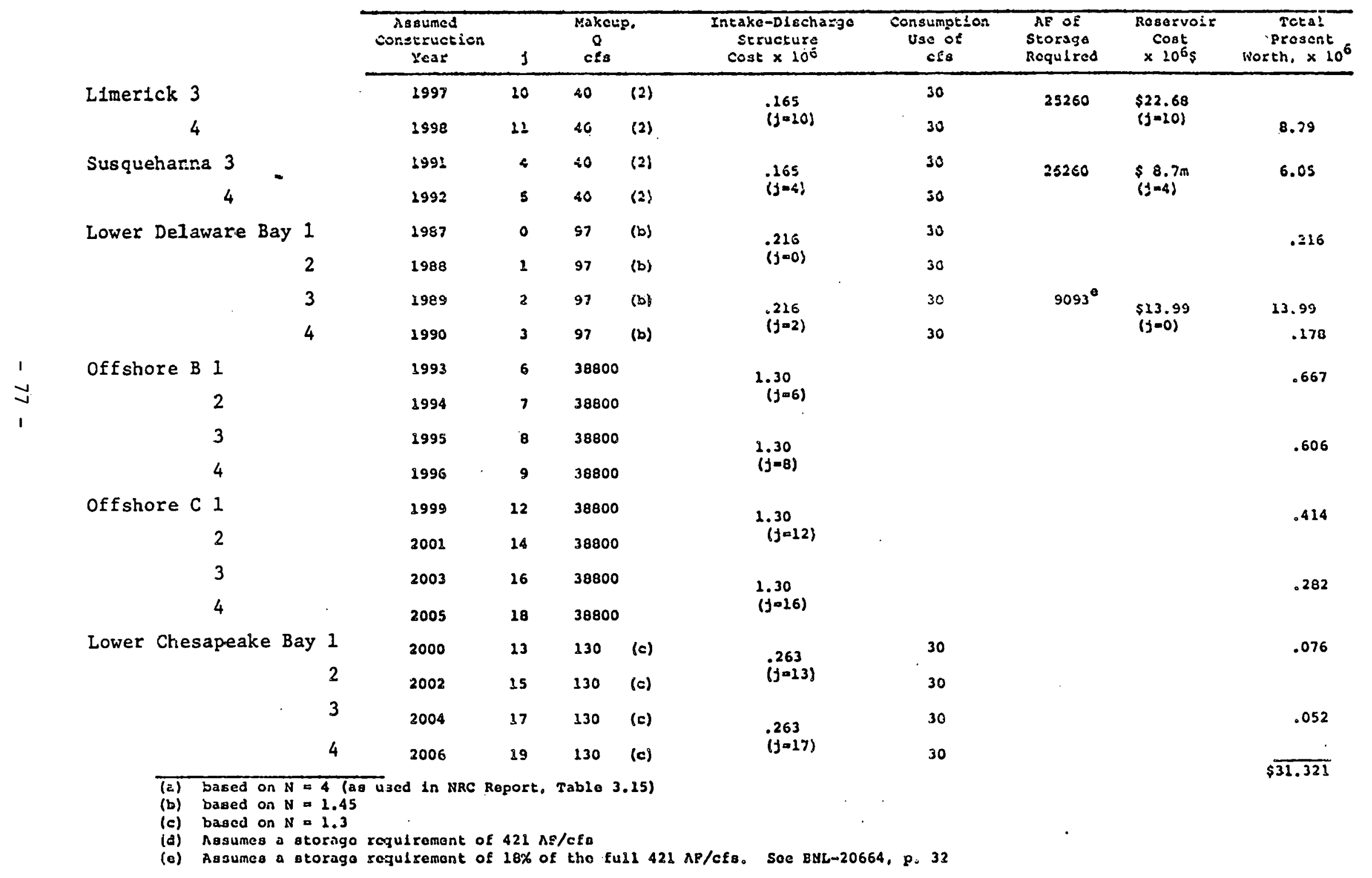


The dispersed case total present worth. of Table 20, and the present worth of the corresponding NEC alternatives (Tables 12,13 , and 14 ), can be summarized as follows:

\begin{tabular}{lc}
\multicolumn{1}{c}{ Site } & Present Worth, $\mathbf{x} 10^{6}$ \\
Fort Dix & 208 \\
Inland & 109 \\
Bay & 585 \\
Dispersed Case & 31
\end{tabular}

This confirms the perhaps rather obvious observation that an NEC located several miles finland would necessitate substantially higher water conveyance rosts than comparatle dispersed sites lncated cloee to their water sources. Even the significant cost of reservoir construction for flow augmentation, necessary for the freshwater dispersed sites, is small in comparison to the NEC conduit costs.

NOTES TO CHAPTER VII

1. P. Meier and D. Morrel1 "Tssues in Cluotcred Nuclear S1r1ng: A Compariosn of a Hypothetical Nuclear Energy Center in New Jersey with Dispersed Nuclear Siting", BNL 50561, Brookhaven National Laboratory, Upton, New York, June 1976.

2. Ibid, Chapter III. 
CHAPTER VIIT

SITING TRADE-OFFS

A question of some interest concerns the trade-offs between electrical transmission and cooling water conveyance. Electric utilities appear to be quite sensitive to the transmission distance between a new generating facility and its load points, and have on numerous occasions objected to a more distant site location mandated on environmental grounds, citing significant increases in transmission cost. ${ }^{1}$ In the case of an ocean County NEC, it is clear that the Fort Dix Site is closest to the load centers, and the Bay Site the most distant; the germane question here, then, is how the increase in water conveyance cost incurred by a move from the Bay Site to the Fort Dix Site compares with the decrease in transmission costs of the same relocation. In other words, which is the cheaper to move, electrons or water?

The General Electric analysis of transmission for an Ocean County NEC includes a detailed schedule. for construction of $500 \mathrm{Kv}$ lines from the NEC to the Deans, Larabee, and New Freedom substations. ${ }^{2}$ The location of these substations in relation to the PJM $500 \mathrm{Kv}$ Network is illustrated on Figure 13, as based on the General Electric Report. The G.E. analysis assumes straight line distances to these substations from the NEC (assumed to be at the Inland Site location).

For purposes of this analysis, we have recomputed the distances from each of the three NEC locations studied in this report to the G.E. specified substations, routing the lines in such a way as to avoid state Forest lands. As can be seeu from Figurc 13, this dnes result in somewhat longer than straight line distances in some cases. Then using the construction schedule stated by G.E., and using their cost data for circuit miles, ${ }^{3}$ one can compute the present worth of the transmission investments over the twenty-year period. One can similarly compute the present worth of the water conveyance system investments over the same time period to each of the three sites. 


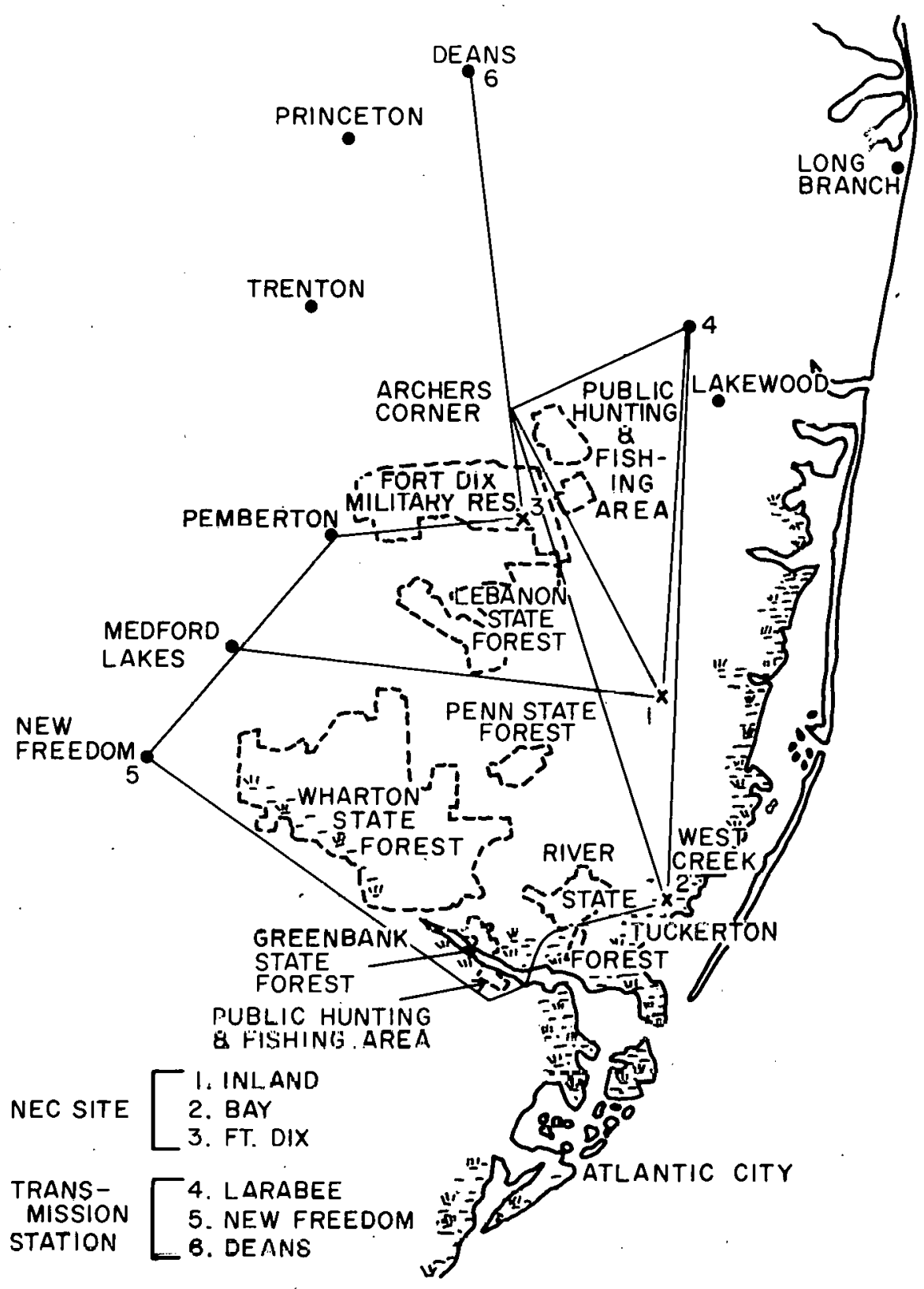

Figure 13. Transmission routes. Source: Meler \& Morel1, notc 6 . 
Tables 21 and 22 show the results of this analysis. In both evaporatively and once-through cooled cases, water transmission costs dominate electrical transmission costs. Thus, for example, in the case of Table 21 for evaporative systems, moving from inland to Ft. Dix entails a transmission cost saving of $\$ 12.3$ million, completely outweighed by the additional water conveyance cost of $\$ 99$ million. In the once through case, this effect is even stronger (see Table 22).

A final comparison of some interest is between the assumed tunneling cost and that incurred by a cut-fill conduit at the surface. Using the same parameters (for right-of-way, excavation and pipe costs) as used in the NRCNECSS, ${ }^{4}$ the computed water conveyance system costs are displayed on Tables 23 and 24. We note first that the surface conduit cost is about $30 \%$ lower than the tunnel cost for evaporatively cooled systems (compare Table 23 with 21), but almost an order of magnitude lower in the once-through case (compare Table 24 with 22). 5 Also note that the water conveyance cost again dominates the electrical transmission costs in both the evaporative and once-through case.

This comparison between the two modes of water conveyance system is somewhat tenuous, however, in view of the great uncertainties that underlie the cost functions used in analysis. In particular we would stress again that the use of an average cost function for tunnelling poses some difficulty in an area of uncertain engineering geology; but by the same token, the use of an average figure for right-of-way cost ( $\$ 500 /$ acre) may also be inappropriate. 
Table 21

COMPARISON OP TRUNSHISSYOA ARD MATRR CORVBYABSB COST POR EVAPORATIVELY' COOLED NBC'• AED-BORED TURARLS
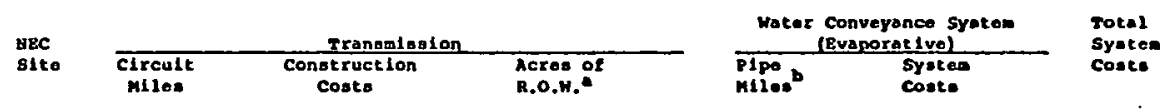

$\begin{array}{lllllll}\text { Bay } & 789 & & 165 & & 16569 & \\ 4 & & -175 & & -30.7 & & -3695\end{array}$
20
60
225

$\begin{array}{ccccccc}\text { Inland } & 514 & & 134 & & 12894 & \\ 6 & & -164 & & -12.3 & & -3486\end{array}$

pt. Dix 448

SOTES, (a) agsumes 275 tt. Wlath per clrcult - 21 acros/allo

(b) actumes $n-1$.

Table 22

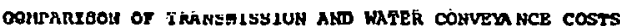
FOR OHCE-THROUGH COOLED REC' AND BORED TUNRELS

Hec
site

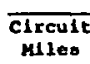

Circuit
mles

789

Bay

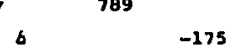

Inland 614

a - ins

Ft. Dix 448

122

165

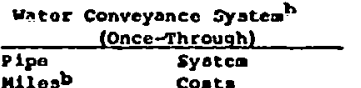

Totsi.

System

coses

10

750

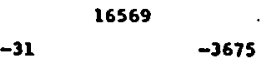

10

$+10$

ses

513

20

1098

1232

40

2085

2267

Notesi (a) ossumes $175 \mathrm{ft}$. width per clrcult = 21 acres/mile

(b) asaumas 2 .

Table 23

\begin{tabular}{|c|c|c|c|c|c|c|c|c|c|c|}
\hline \multirow{3}{*}{$\begin{array}{l}\text { NEC } \\
\text { Sitto }\end{array}$} & \multicolumn{10}{|c|}{$\begin{array}{l}\text { COMPARISON OP TRANSMISSION AND HATER CONMPYANP COTTE } \\
\text { EUR EUAPORAT̈IVE SYSTEMS AND BURIED CONDUITS }\end{array}$} \\
\hline & \multicolumn{6}{|c|}{ Transmias1on } & \multicolumn{3}{|c|}{$\begin{array}{l}\text { Water Conveyanco Syates } \\
\text { Evaporat } 1 \text { ve. Buried Condulte }\end{array}$} & \multirow{2}{*}{$\begin{array}{l}\text { Toto: } \\
\text { Cose: }\end{array}$} \\
\hline & $\begin{array}{r}\text { Circult } \\
\text { Miles }\end{array}$ & & $\begin{array}{l}\text { Construction } \\
\text { Conta }\end{array}$ & & $\begin{array}{l}\text { Acres of } \\
\text { R.O.H. }\end{array}$ & & $\begin{array}{l}\text { Plpe } \\
\text { miles }\end{array}$ & & $\begin{array}{l}\text { Syated } \\
\text { Costs }\end{array}$ & \\
\hline Bay & 789 & & 165 & & 16569 & & 10 & & 41 & 206 \\
\hline$\Delta$ & & -175 & & -31 & & .03673 & & +10 & +36 & \\
\hline Inlana & 614 & & 2.36 & & 12894 & & 20 & & 75 & 209 \\
\hline 6 & & -164 & & -12 & & -3486 & & +20 & +65 & \\
\hline Pt. D1x & 448 & & 122 & & 9400 & & 40 & & 140 & 262 \\
\hline
\end{tabular}

Table 24

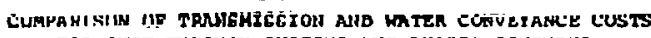
FOR ONCE-THROUGH SYSTENS AND BURIED CONDUITS

\begin{tabular}{|c|c|c|c|c|c|c|}
\hline \multirow{2}{*}{$\begin{array}{l}\text { NEC } \\
\text { Site }\end{array}$} & \multicolumn{6}{|c|}{ Transmiootion } \\
\hline & $\begin{array}{l}\text { Circuit } \\
\text { Miles }\end{array}$ & & $\begin{array}{l}\text { Construction } \\
\text { Costa }\end{array}$ & & $\begin{array}{l}\text { Acres of } \\
\text { B.n.w. }\end{array}$ & \\
\hline${ }_{b}^{\text {Bay }}$ & 789 & -175 & 165 & -30 & 16569 & -3675 \\
\hline $\begin{array}{c}\text { Inland } \\
\Delta\end{array}$ & 614 & -164 & 134 & -12 & 12894 & -3486 \\
\hline
\end{tabular}

Ft. Dix 448
122
Water Conveyance Sygtem Oüco-Tlisuugli, Buriea concusts Pipe System

$\begin{array}{lllll}10 & +10 & 108 & & 273 \\ 20 & & 198 & & \\ 40 & & 371 & & 332\end{array}$


1. For further discussion on this point, and some specific examples, see e.g. P. Meier, "Energy Facility Location: A Regional Viewpoint", Report BNL 20435, Energy Policy Analysis Group, Brookhaven National Laboratory, Upton, New York, August 1975.

2. L.L. Garver, et al., "Transmission Expansions as Affected by Energy Centers", Report by the Electric Utility Systems Engineering Department of the General Electric Company to NRC, Office of Special Studies, Washington, D.C., November 1975.

3. The cost per circuit is given as $(0.38 \times$ distance +9.2$)$ million dollars. By the tome of completion, $10500 \mathrm{Kv}$ lines would go to Larabee, 2 to Deans, and 3 to New Freedom.

4. See Section 2.6 for the numerical values used.

5. Compare this to the analysis at the Seabrook Nuclear Station, where the cost of a buried system was estimated at $\$ 81$ million, as opposed to $\$ 57$ million for a system tunnelled through hard rock. Since the Seabrook tunnel for a two unit once-through facility is of comparable capacity to that required for a 20 unit evaporatively cooled. NEC, our results appear to be reasonable, at least in order of magnitude. (See "Seabrook Station Units 1 and 2, Final Environmental Statement," U.S. Atomic Energy Commission, Directorate of Licensing, December 1974, p. 9-13.).

6. P. Mefer and D. Morrell "Issues in Clustered Nuclear Siting: A Comparison of a Hypothetical Nuclear Energy Center in New Jersey with Dispersed Nuclear Siting", BNL 50561, Brookhaven National. Laboratory, Upton, New York, June 1976. 